\title{
Strategic Option of ICT Driven Development Trajectory in Myanmar
}

\author{
Khin Sandar \\ National University of Singapore, Singapore. \\ Chihiro Watanabe \\ National University of Singapore, Singapore, University of Jyvaskyla, Finland, \\ International Institute for Applied Systems Analysis (IIASA), Austria.
}

\begin{abstract}
While Myanmar shared one of the richest lands in South Asia with affluent natural resources and qualified human resources, it has suffered long lasting economic stagnation since 1962. However, conspicuous economic growth, after the take off strategy 1997 (1999-2007), was highest among 10 member countries of ASEAN, China and India, and has demonstrated their potential ability to transform their constraints into a springboard for innovation. This reminds us of Information Communication Technology (ICT) driven development trajectory demonstrated by the world ICT top leaders, Finland and Singapore. Both transformed their indigenous constraints into India, and has springboard for ICT advancement and prompts us a hypothetical view that such a trajectory could be a promising strategic option for Myanmar in awaking its latent competitive power. This paper presents an empirical analysis considering ICT driven developing trajectory in 146 countries. The analysis involved four major steps. Firstly, Myanmar's possible development trajectory was estimated, based on innovation diffusion theory, by identifying its current position in the global ICT versus per capita income development trajectory. Secondly, Myanmar's current position in the global ICT driven economic development trajectory was identified based on the theories of timing of emergence of functionality development and CHASM (deep trench compelling new ventures start-up). Thirdly, given Myanmar's position in anticipating support from ICT advanced countries for its ICT advancement, effects of support were analyzed by decomposing the governing factors to ICT advancement. In addition, Myanmar's institutional identity supportive to effective utilization of ICT support was analyzed. Fourthly, based on the foregoing analyses together with the analysis of the similarity and disparity between world ICT top leaders, Finland and Singapore, possible scenarios for Myanmar's ICT driven development trajectories, growth oriented or welfare and happiness seeking were compared.
\end{abstract}

Keywords: Myanmar, ICT driven development trajectory, institutional source, coevolutionary acclimatization, CHASM

\section{INTRODUCTION}

\section{ICT and Economic Development Trajectory}

Nowadays, the strategic use of Information and Communication Technology (ICT) plays a critical role for socioeconomic development of a nation and is a key to shape the nation's state in terms of business, academics, politics, communication, innovation and has a direct effect on the nation's economy. Myanmar is pressed by other nations especially by ASEAN nations for its development trajectory, particularly the ICT driven development trajectory.

Journal of Technology

Management for Growing Economies

Vol. 5 No. 2

October 2014 pp. $89-127$

\section{CHITKARA 司 UNIVERSITY}

C 2014 by Chitkara University. All Rights Reserved. 
Sandar, K.

Watanabe, C.
The effective utilization of ICT governs the development trajectory of Myanmar and this utilization can be expected with ICT advanced countries in a way to construct a co-evolutionary acclimatization (Watanabe et al., 2014). Lessons for it can be expected by contrasting trajectories in world ICT top leaders: Finland and Singapore (WEF, 2013b). Both share many similarities such as top rankings in the world not only in ICT but also in educational and international competitiveness. However, both share contrasting disparity as economic growth oriented trajectory in Singapore and welfare and happiness seeking trajectory in Finland (WEF, 2013a).

After year 2000, Myanmar introduced ICT in the nation, especially in academic, economic and government sectors, aiming to develop its application effecting in all areas of the country in which it is needed. The development of ICT in Myanmar actually seems to be slow to cover the whole nation of the fourteen states and divisions. (Han, 2010; MCPT, 2011).

Myanmar incorporates institutional strength in effective utilization of the support provided for ICT advancement (Oo, 2012; UNDP, 2013). The main infrastructures such as Myanmar telecoms, mobile and the Internet are to be focused as a major sector to liberalize and open for the foreign investment (Evans, 2013). With strengthening legal and institutional frameworks, which are the pillars to support economic success, many problems can be resolved for overall development and improvement (Kyi et al., 2000).

Bi-polarization can be observed in the global competitiveness race between ICT advanced economies and ICT growing economies (Zhao et al., 2013). Contrary to a conspicuous economic growth in the latter, the former suffers from greater stagnation (Cowen, 2011) except Singapore (Watanabe, 2013; Zhao et al., 2013). From this bi-polarization phenomena, identification of the current position of global ICT advancement level can be identified by per capita income development trajectory (Zhao et al., 2013).

Given that nations institutional systems govern their development trajectory options (Watanabe, 2009; Watanabe and Zhao, 2006), this paper analyzes co-evolutionary relationship between institutional systems and ICT driven development trajectory in Finland and Singapore thereby extract lessons suggestive to Myanmar for its trajectory formation based on its indigenous institutional systems. Contrast between happiness and welfare seeking trajectory in Finland and growth oriented trajectory in Singapore

Journal of Technology Management for Growing Economies, Volume 5, Number 2, October 2014 
(WEF, 2013a) would be suggestive for Myanmar towards shaping its ICT driven developing trajectory.
Strategic Option of ICT Driven

\section{Myanmar's Development Trajectory}

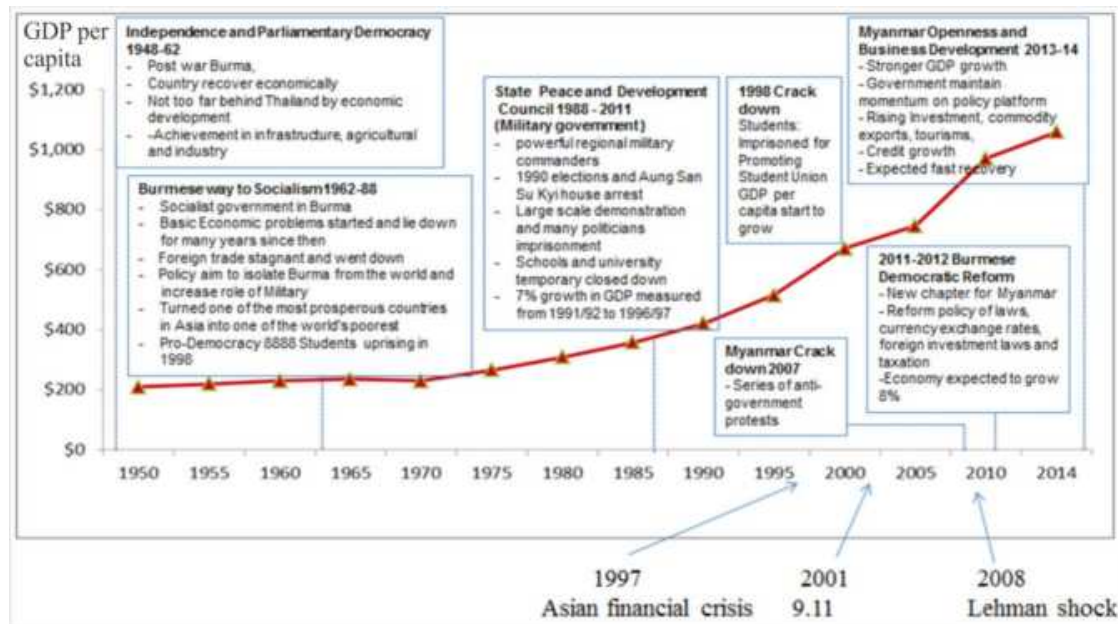

Figure 1: Economic Development Trajectory in Myanmar (1950 - 2014)

Sources: World Economic Outlook Database (IMF, annual issues), A Vision and Strategy Economic Development of Burma (World Bank, 2000) and authors'estimate.

Figure 1 illustrates Myanmar's economic development trajectory over the period 1950-2014. During post war period 1948, Burma (Myanmar) rebuilt the nation with some foreign assistance. By 1958 , the nation was largely beginning to recover economically. From 1962 to 1988, Burma was under Socialist government and the administration changed to the Burmese Way of Socialism. It was an economic treatise written in April 1962 by the Revolutionary Council, shortly after the coup, as a blueprint for economic development, reducing foreign influence in Burma, and increasing the role of the military. Since then, slowly, Burma had turned from one of the most prosperous countries in Asia into one of the world's poorest countries in the world. However, it may had served towards increasing the domestic stability and keeping Burma from being entangled in the Cold War struggles that affected other Southeast Asian nations.

There was a democracy movement in 1988 which was suppressed by the military junta and the State Law and Order Restoration Council (SLORC) which was established later on. SLORC renamed the country as Union of Myanmar from Burma. In 1997, SLORC was abolished and reconstituted as the State Peace and Development Council (SPDC) consisting of the powerful 
Sandar, K.

Watanabe, C.

regional military commanders. SPDC introduced the take off strategy in 1997 consisting of innovation, institutional change, higher education and technological readiness endeavor leading to a conspicuous economic growth.

Looking back to the strategies and actions paving the way for this rapid economic growth, it found that one of the strong factors can be a series of liberalizing market-oriented economic policy reforms. These reforms led to $7 \%$ annual GDP growth in the period 1991-1997. In fact, since 1990 the SLORC implemented market-oriented economic policy reforms. SLORC opened the economy by giving expansion permit to the private sectors to attract foreign investment. This opened up external trade to private enterprise and increased the exports and importers in Myanmar in 1997. In addition, there were some foreign garment industries and factories in Myanmar, exporting to the large markets of Europe and US. In addition, the natural gases from Myanmar were exported to foreign countries such as Thailand, India and China. There were also some private income transfers from overseas which includes Burmese people working abroad and Burmese seamen with foreign wages.

In 2011, a new chapter of Myanmar had opened with Burmese Democratic Reform. A number of notable changes in economic environment started an ongoing series of political, economic and administrative reforms. Myanmar has embarked on policy reforms of anti-corruption laws, currency exchange rates, foreign investment laws and taxation. Economic sanctions had been eased and lifted and foreign investment increased from US\$300 million in 2009-10 to US $\$ 20$ billion in 2010-11. The large inflow of capital resulted in a stronger valuation of the kyat (Burmese currency) by about 25 percent. In response, the government relaxed import restrictions and abolished export taxes. Another area of foreign investments came into the tourism industry because Myanmar has great tourist potential attractions in many areas especially due to the wealth of Buddhist temples.

In 2013-2014, the openness and business development of Myanmar continued with a stronger GDP growth. The government maintains the momentum on policy platform. There are many improvements seen such as rising foreign investment, higher commodity exports and wider tourisms industries. Subsequently, the credit will grow and lastly Myanmar is expected for the fast recovery (WEF, 2013a).

As a consequence of such policy reforms, Myanmar demonstrated rapid economic growth from the late 1990s as demonstrated in Figure 2. Figure 2 illustrates the trend in Myanmar's real GDP growth from 1980 to 2013. While its economic growth dramatically stagnated in 1998 and 1998 due to Asia financial crisis in 1997 and anti-government protest, it turned out to a

Journal of Technology Management for Growing Economies, Volume 5, Number 2, October 2014 
conspicuous growth from 1999 supported by the series of policy reforms and the take off strategy in 1997.

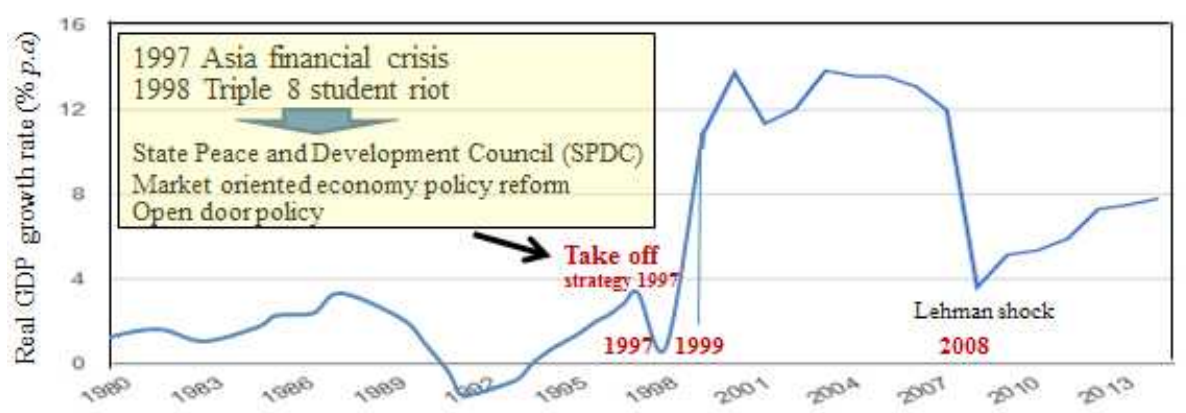

Figure 2: Trend in Real GDP Growth Rate in Myanmar (1980 - 2013) Source: World Economic Outlook Database (IMF, annual issues).

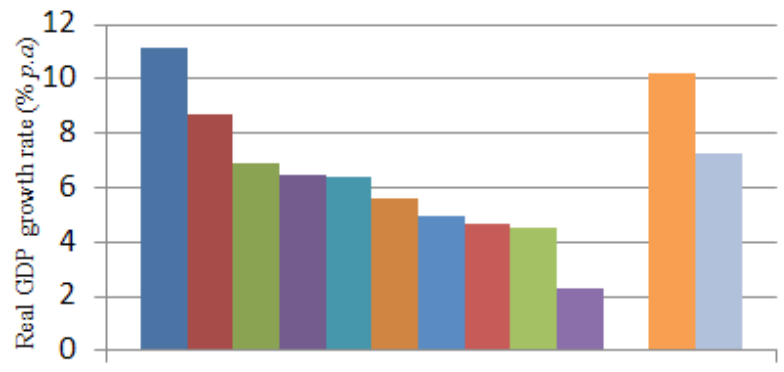

Strategic Option of ICT Driven

Figure 3: Average Real GDP Growth Rate in ASEAN 10 Countries, China and India (1999-2007)

Source: World Economic Outlook Database (IMF, annual issues).

Figure 3 compares the average real GDP growth rate in ASEAN 10 countries, China and India over the period 1999-2007. Looking at the table inscribed in figure 3 we note that Myanmar's economic growth is the highest among ASEAN countries and even higher than China and India. The conspicuous growth suggests Myanmar's potential ability to transform its constraints into a springboard for innovation.

\section{ICT Driven Economic Development}

Figure 4 illustrates ICT driven economic development trajectory in 100 countries in 2011, which demonstrates dramatic advancement of ICT has led the ICT driven logistic growth. 
Sandar, K.

Watanabe, C.

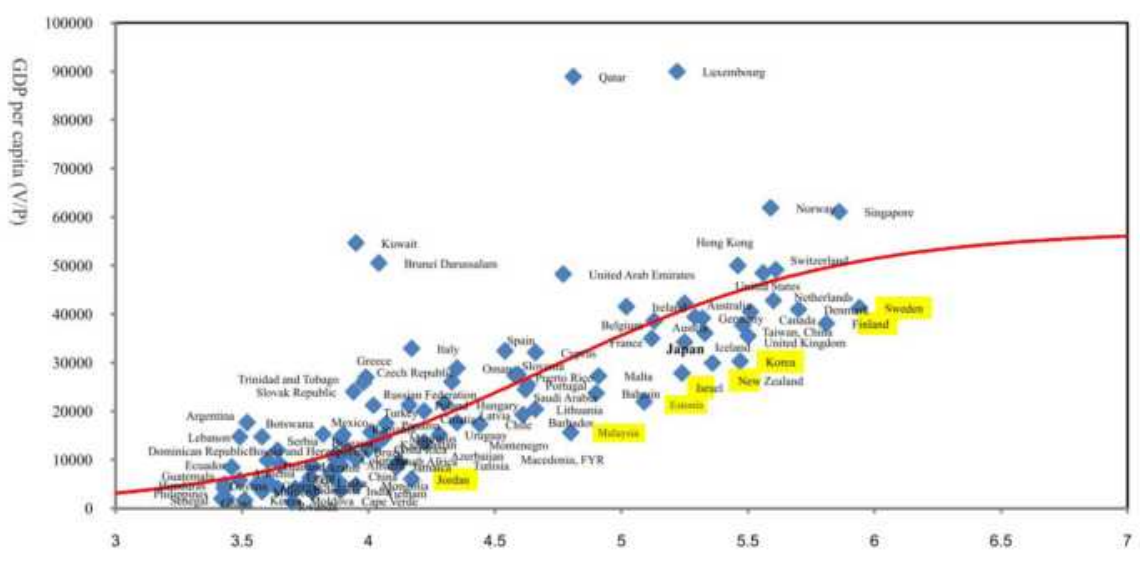

ICT by Networked Readiness India (NRI)

Figure 4: Global ICT Driven Economic Development Trajectory in 100 Countries (2011)

Sources: The Global Information Technology Report 2012 (World Economic Forum, 2012), World Economic Outlook Database (IMF, 2012).

$\frac{V}{P}=\frac{N}{1+b e^{-a N R I}}+\begin{aligned} & V / P: \text { GDP per capita, } N: \text { carrying capacity, } N R I: \text { Networked readiness index, } \\ & D_{l}, D_{2}: \text { dummy variables, and } a, b, c, d: \text { coefficients. }\end{aligned}$

\begin{tabular}{crrrrr}
\hline $\mathrm{N}$ & $\mathrm{a}$ & \multicolumn{1}{c}{$\mathrm{b}$} & $\mathrm{c}$ & $\mathrm{d}$ & \\
\hline 57239 & 1.68 & 2697.28 & 46434 & -12913 & adj $\cdot R^{2} 0.885$ \\
$(9.62)$ & $(7.58)$ & $(9.80)$ & $(14.54)$ & $(-5.25)$ & \\
\hline
\end{tabular}

Figure 4 demonstrates dramatic advancement of ICT by NRI as a proxy of nation's ICT advancement which consists of environment (political and regulatory environment, business and innovation environment), readiness (infrastructure and digital content, affordability), usage (individual usage, business usage, government usage) and impact (economic impact, social impact) (WEF, 2013b).

\section{Similarity and Disparity between Singapore and Finland}

Figure 5 compares levels of economic development and ICT as well as institutional systems between Singapore and Finland with similar population of 5 million. 


\begin{tabular}{|l|lc|}
\cline { 2 - 3 } \multicolumn{1}{c|}{} & \multicolumn{1}{c|}{$\begin{array}{c}\text { Singapore } \\
\text { High level of economic development }\end{array}$} & $\begin{array}{l}49.3 \\
\text { High level of Network develop/depend }\end{array}$ \\
Highly organized institutional systems & NRI No.2 \\
& $\begin{array}{l}\text { Efficiency of legal framework } \\
\text { Transparency of government Policy making } \\
\text { Ethical behavior of firms } \\
\text { Quality of the educational system }\end{array}$ \\
\hline
\end{tabular}

Strategic Option of ICT Driven

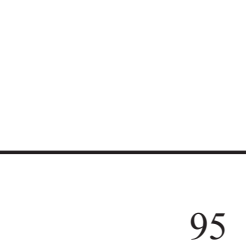

\section{High level of competitiveness}

No. 2

No.3 in the world

Figure 5: Similarity between Finland and Singapore

Sources: World Economic Outlook Database (IMF, 2013). The Global Information Technology, Report 2013 (WEF, 2013b), The Global Competitiveness Report 2013-2014 (WEF, 2013a).

Looking at Figure 5 we note the similarities between both countries. Both have high level of economic development; high level of network readiness and highly organized institutional systems; strong innovation and institutional framework and strong focus on education and training. As a result, both are ranked high in terms of global competitiveness. ICT industry is an important sector for its economic growth and has properly functioning and highly transparent public institutions. Finland ranked number one in Europe and number two in the world according to ICT industry competitiveness index 2011. Singapore is number one in South East Asia.

Figure 6 demonstrates the disparity between Finland and Singapore. Comparing cultural dimension of the nations, Singapore has a high Power Distance and Masculinity. It shows that people have accepted the power level inequality and people of Singapore are competitive, assertive, materialistic, ambitious and attractive to power. Finland is different from Singapore and ranked higher in terms of individualism and uncertainty avoidance. 
Sandar, K.

Watanabe, C.

Cultural dimension of the nations

Economic development strategy

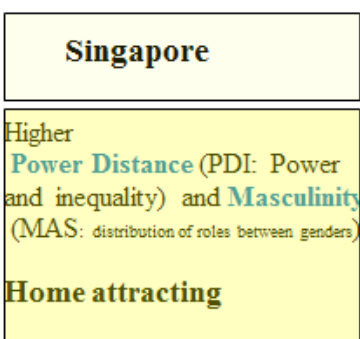

Finland

Higher

Individualism (IDV)

and Uncertainty

Avoidance (UAI)

Abroad exploring

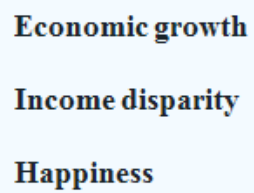

\begin{tabular}{|l||l}
\hline Sustainably conspicuous & Stagnating \\
High & Low \\
Low & High \\
\hline
\end{tabular}

Figure 6: Disparity between Finland and Singapore

Sources: Cultures and Organizations (Hofstede, 1991), Distribution of Household Income by Source (ILO, 2013), World Happiness Report (UN, 2012).

The economic growth of Singapore is sustainably conspicuous while Finland is stagnating. The income disparity is high for Singapore and lower in Finland. Singapore has been remarkable due to low level of happiness while Finland has high ranking even in better life index and people in Finland work for 1684 hours a year, which is less than the OECD average of 1776 hours.

\section{Theory of Diffusion, Development Trajectory, Acclimatization and Cul- tural Dimension}

\section{Diffusion theory}

Rogers (1962) defined diffusion as the process by which an innovation is communicated through certain channels overtime among the members of a social system. Rogers also identified four main elements in the diffusion of innovations viz., innovation features, communication channels, time and social system. The diffusion process is actually quite similar to the contagion process of an epidemic disease. There are five established adopter categories viz., Innovators (2.5\% of whole consumption), Early Adopters (similarly, $13.5 \%$ ), Early Majority (34\%), Late Majority (34\%) and Laggards (16\%). This theory provides significant insights into the ICT driven development trajectory in the context of cultural dimension and possible impediments to the development. 


\section{ICT Driven Development Trajectory}

The advancement in technology, development of computers, information technology (IT), transport and communications and more recently, rapid growth in the use of the internet, mobile and smart phones has obvious impact on business. Thus, the ICT industry has made important contribution to the global economy. The ICT sector was considered important in EU Lisbon Objectives and Europe 2020 Strategy (EU, 2010). Development trajectory of innovative goods and services has been generally analyzed by their diffusion trajectory as a function of institutional systems (Watanabe et al., 2004). The forefront of the new stream in global ICT competition race was analysed later (Watanabe et al., 2014). Empirical analyses focusing on ICT driven development trajectory in 100 nations and also 500 global ICT firms were undertaken. Based on comparative analysis between resilient and no-resilient trajectories, suggestions for business model were extracted. It was observed that dramatic advancement of ICT has led to ICT driven logistic growth in both nations and global ICT firms.

\section{Bi-polarization}

Watanabe et al (2014) demonstrated the logistic growth transforming into bipolarization among 100 nations and 500 global ICT firms. Bi-polarization was illustrated to find the split between two sets of economies where 70 nations, which are growing in terms of ICT, have been enjoying a virtuous cycle between ICT advancement and its marginal productivity increases as generally anticipated. ICT advanced 30 nations have fallen into a pit of a vicious cycle as IT advancement decreases its marginal productivity against anticipation.

The excessive technology driven trajectory may lead to a pit of a vicious cycle between technology development and marginal productivity decline (Tokumasu et al., 2008). This can be attributed to unique nature of ICT that incorporates such nature as declining marginal productivity of technology (Watanabe et al., 2014) as a consequence of price decrease typically observed in the advancement of the internet with free of charge services (Cowen, 2011).

\section{Co-evolutionary Acclimatization}

The technology driven development trajectory in global ICT firms may bipolarize between R\&D increasing firms which enjoy a virtuous cycle and R\&D matured firms which suffer a vicious cycle (Watanabe et al., 2014). In order to overcome such a vicious cycle, R\&D matured firms necessitates the co-evolutionary acclimatization structure which harness the vigor of emerging power of counterparts both in home and advanced countries and growing

Journal of Technology Management for Growing Economies, Volume 5, Number 2, October 2014
Strategic Option of ICT Driven 
Sandar, K.

Watanabe, C.

economies in a co-evolutionary way (Zhao et al., 2013). This structure supports $\mathrm{R} \& \mathrm{D}$ increasing firms by facilitating the opportunities for sales increase enabling them to invest higher R\&D. This co-evolutionary acclimatization structure leads a way to resilient market creation which satisfies both efficiency and resilience by maximizing synergy effects between them (Watanabe et al., 2014).

\section{CHASM}

Moore $(1991,1999)$ shows that in the technology adoption life cycle postulated by Rogers (1962) there exists a deep trench compelling new ventures start-up called CHASM between the early minority (innovators + early adopters) and the early majority. While early minority is willing to sacrifice for the advantage of being first, the early majority waits until they know that the technology actually offers improvements in productivity. The challenge for innovators and marketers is to narrow this CHASM and ultimately accelerate adoption across every segment.

Moore believes visionaries and pragmatists have very different expectations, and he attempts to explore those differences and suggest techniques to successfully cross the CHASM including choosing a target market, understanding the whole product concept, positioning the product, building a marketing strategy, choosing the most appropriate distribution channel and pricing.

\section{Emergence of Functionality Development}

Mahajan et al (1990) identified that the timing when functionality development emerges corresponds to the timing when early minority transfers to early majority. This finding suggests a significant insight to new ventures and also the least developing countries including Myanmar and their autonomous development vision.

\section{Cultural Dimension}

Hofstede (1991) analyzed a large data base of employee values scores collected by IBM between 1967 and 1973 covering more than 70 countries. Hofstede (1991) identified cultures and organizations of the nations by categorizing them into five dimensions viz., power distance, individualism, masculinity, uncertainty avoidance, and long-term orientation (see Appendix II). These postulates provide substantial insight towards assessing the possibility of development trajectory by assimilating the advancement of ICT.

On the basis of the aforementioned review of literature, this paper analyses Myanmar's strategic option of ICT development trajectory focusing on

Journal of Technology Management for Growing Economies, Volume 5, Number 2, October 2014 
(i) Global ICT development trajectory,

(ii) Effects of the support for ICT advancement, and

(iii) Possible Scenario for Myanmar's ICT Driven Development Trajectories.

The next section outlines the analytical framework. Thereafter, results of empirical analyses are demonstrated, which includes the consequence of ICT advancement. In the section after this, Myanmar's possible development trajectory is discussed. The last section briefly summarizes noteworthy findings, policy suggestions and points of the future work.

\section{ANALYTICAL FRAMEWORK}

\section{Overcoming CHASM for Autonomous Development}

Figure 7 outlines the analytical framework based on preceding theories on innovation diffusion (Rogers, 1962), timing of the emergence of functionality development (FD) (Mahajan et al., 1990), CHASM (Moore, 1991, 1999), bi-polarization of logistic growth (Tokumasu and Watanabe, 2008) and coevolutionary acclimatization (Watanabe et al., 2014).

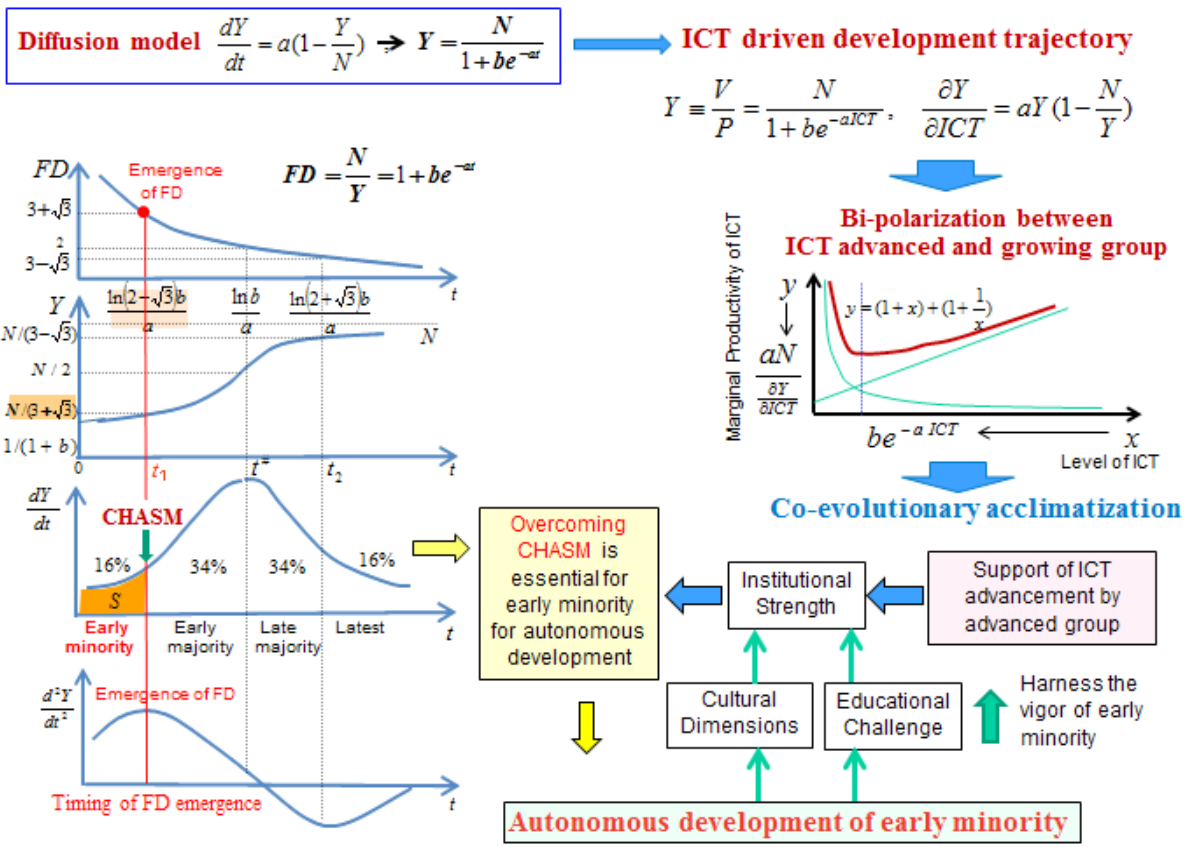

$Y$ : GDP per capita; $N$ : carrying capacity; $t$ : time; $a$ : diffusion velocity; $b$ : initial level of diffusion.

Figure 7: Analytical Framework 
Sandar, K.

Watanabe, C.

Mahajan et al (1990) identified that the timing when FD emerges corresponds to the transition from early minority (which shares $16 \%$ of whole diffusion volume as postulated by Rogers (1962)) to early majority (similarly $34 \%$ ) and its FD level is equivalent to $3+\sqrt{3}$. Moore postulated that new venture start-up should overcome CHASM (deep trench compelling its entrepreneurial success) which appears at the same time.

Currently, Myanmar belongs to early minority in the global ICT driven economic development trajectory, therefore overcoming CHASM is essential for its autonomous development.

\section{Bi-polarization of Logistic Growth}

Since, logistic growth trajectory can be developed to a bi-polarization trajectory which is described in the following mathematical expression(Tokumasu and Watanabe, 2008) and global wide ICT development can be traced proportional to time trend $t$, ICT driven economic development trajectory in the world split to bi-polarization as illustrated on the right hand side of Figure 7 (Watanabe et al., 2014).

$$
\begin{aligned}
& \frac{d Y}{d t}=a Y\left(1-\frac{Y}{N}\right)=\frac{a N}{1+b e^{-a t}}\left(1-\frac{1}{1+b e^{-a t}}\right)=\frac{a N}{\left(1+b e^{-a t}\right)} \cdot \frac{b e^{-a t}}{\left(1+b e^{-a t}\right)} \\
& =\frac{a N}{\left(1+b e^{-a t}\right)} \cdot \frac{1}{\left(1+b e^{a t}\right)}=\frac{a N}{\left(2+b e^{-a t}+\frac{1}{b e^{-a t}}\right)} \\
& \frac{a N}{\frac{d Y}{d t}}=2+b e^{-a t}+\frac{1}{b e^{-a t}} \\
& y=(1+x)+\left(1+\frac{1}{x}\right) \quad y \equiv \frac{a N}{\frac{d Y}{d t}}, x \equiv b e^{-a t}
\end{aligned}
$$

Under ICT driven economy where ICT initiated logistic growth trajectory governs,

$$
\begin{aligned}
& Y=F(t)=F(I C T) \text { and } \frac{d Y}{d t}=\frac{d Y}{d I C T}=\frac{\partial Y}{\partial I C T} \cdot \frac{d I C T}{d I C T}=\frac{\partial Y}{\partial I C T} \quad . \text { Thus, } \\
& S=\int_{0}^{t_{1}} \frac{d Y}{d t} d S=[Y]_{0}=\left[\frac{N}{1+b e^{-a t}}\right]_{0}^{t_{1}}=N\left[\frac{1}{3+\sqrt{3}}-\frac{1}{1+b}\right]
\end{aligned}
$$

where, S: whole production outcome in the period of the early minority (innovators + early adopters).

Given the initial level of diffusion $\mathrm{N} /(1+\mathrm{b})=0.05, \mathrm{~S} / \mathrm{N}=0.16$ and equivalent to the foregoing timing.

Journal of Technology Management for Growing Economies, Volume 5, Number 2, October 2014 
$x=b e^{-a I C T}, y=\frac{a N}{\frac{\partial Y}{\partial I C T}}$

Strategic Option of ICT Driven

$x$ and $y$ in Figure 7 signify ICT (level of NRI) and marginal productivity of ICT increase towards the origin of the coordinate axes.

Consequently, ICT advanced countries suffer a vicious cycle wherein further advancement of ICT results in decreasing its marginal productivity while ICT growing countries enjoy a virtuous cycle between ICT advancement and its productivity increase.

\section{Co-evolutionary Acclimatization}

Co-evolutionary acclimatization is a solution of the bi-polarization dilemma. Since, further advancement of ICT in ICT advanced countries results in decreasing their marginal productivity, such efforts should be addressed to the support of ICT advancement in ICT growing countries which leads to increase their economic growth by increasing the marginal productivity through ICT. ICT advanced countries, in turn can harness the growth of ICT growing countries, thereby, further support of ICT advancement in ICT growing countries can be enabled leading to constructing the win-win relationship between two economies as illustrated in Figure 8 (Watanabe et al., 2014).
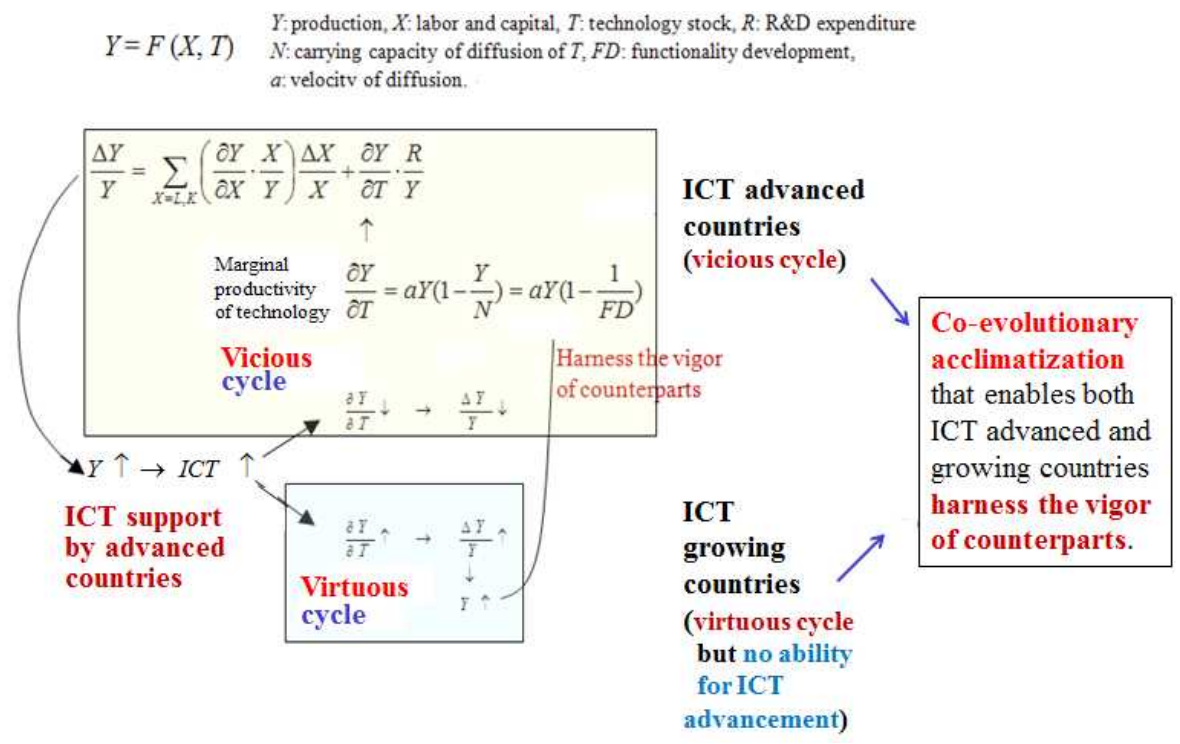

Figure 8: Scheme of Co-evolutionary Acclimatization in ICT Driven Development Trajectory 
Sandar, K.

Watanabe, C.

102

\section{Data Construction}

The analytical framework is designed as illustrated in Figure 7, where the GDP per capita and NRI data were used in epidemic function to get the ICT driven development trajectory of 144 nations. GDP per capita is referred from World Economic Outlook Database (IMF, annual issues) and NRI is referred from the Global Information Technology Report (WEF, 2013b) except for Myanmar and Laos. NRI levels in these two countries can be estimated by the International Telecommunication Union's (ITU) Measuring the Information Society 2013 (ITU, 2013).

Myanmar's cultural dimension can be estimated by means of multi-factors regressions utilizing World Economic Outlook Database (IMF, annual issues) and the Global Competitiveness Report 2013-2014 (WEF, 2013a).

\section{CONSEQUENCE OF ICT ADVANCEMENT}

\section{Global ICT Driven Development Trajectory}

By utilizing NRI in 2012 published by the Global Information Technology Report 2013 (WEF, 2013b) Figure 9 demonstrates ICT driven development trajectory in 144 countries in 2012.

Looking at the Figure 9, we note that majority of 144 countries demonstrate ICT driven logistic growth except for the 8 countries, which can be termed as "abnormal countries" viz., as Luxemburg, Norway, Qatar, Switzerland, Australia, Kuwait, Brunei and Italy. These countries are either show resources dependent conspicuous growth (Norway, Qatar, Australia, Kuwait and Brunei) or show conspicuous economic performance (Luxemburg and Switzerland as good performance and Italy as opposite performance).

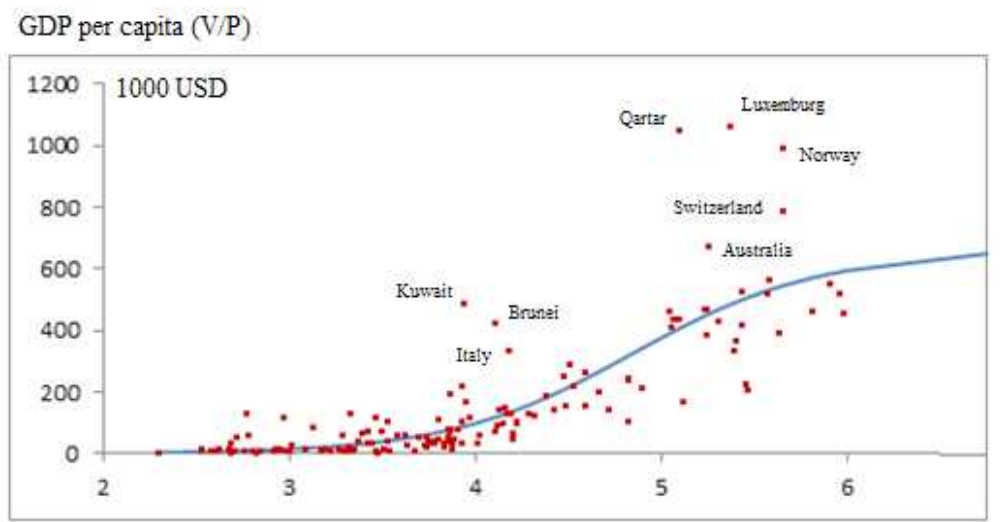

ICT by Networked Readiness Index (NRI)

Figure 9: ICT Driven Economic Growth in 144 Countries (2012)

Sources: The Global Information Technology Report 2013 (World Economic Forum, 2013), World Economic Outlook Database (IMF, 2013)

Journal of Technology Management for Growing Economies, Volume 5, Number 2, October 2014 
Since NRI in Myanmar and Laos are not measured by the aforementioned reports, NRI for these countries are estimated at first.

Since their trajectories are considered to follow the similar ICT driven logistic growth trajectory of 136 countries (excluding the 8 "abnormal countries" out of 144), the logistic growth trajectory is estimated. The results of the estimation are demonstrated in Figure 10 suggesting that NRI levels in Laos and Myanmar are 2.93 (which lies between the NRI levels of Nepal (2.93) and Tanzania (2.93)) and 2.67 (which lies between the NRI levels of Lesotho (2.68) and Yemen (2.63)), respectively. These results are comparable to the order of ICT development index (ID) 2012 measured by the International Telecommunication Union (ITU) in 2013 ("Measuring Information Society", ITU, 2013). ID 2012 of Myanmar and Laos are 1.74 and 2.10, respectively.

Figure 10 outlines the estimation process.

Non-Linear Regression 136 Countries (144-8)

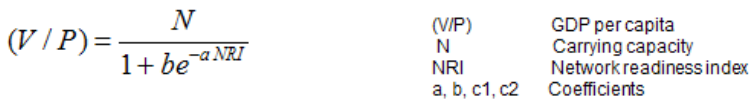

$$
\begin{aligned}
& (V / P)=\frac{57206.138}{1+9267.173 e^{-1.856 N R I}} \\
& \begin{array}{ccc}
\hline N & a & b \\
\cline { 1 - 2 } &
\end{array} \text { adj. } R^{2} 0.850 \\
& (9.98)^{*} \quad(1.37)^{*} \quad(1.32)^{*} \\
& \text { Figures in parenthesis indicate t-value, all demonstrate } \\
& \text { significant at the } 1 \% \text { level } \\
& \text { NRI Myanmar }=-\frac{1}{-1.856} \ln \left[\frac{\frac{57206.138}{(\mathrm{~V} / \mathrm{P})_{\text {Myanmar }}}-1}{9267.173}\right], \quad \text { NRI Lao }=-\frac{1}{-1.856} \ln \left[\frac{\frac{57206.138}{(\mathrm{~V} / \mathrm{P}) \text { Lao }}-1}{9267.173}\right]
\end{aligned}
$$

Strategic Option of ICT Driven

Figure 10: ICT Driven Logistic Growth Trajectory and Estimation of NRI in Myanmar and Laos

Sources: Global Information Technology Report 2013 (World Economic Forum, 2013b), and World Economic Outlook Database 2013 (IMF, 2013).

\section{Bi-polarization between ICT Advanced Countries and ICT Growing Countries}

Following the preceding analyses (Zhao et al., 2013, Watanabe et al., 2014), in line with the bi-polarization of logistic growth as indicated earlier, based on the foregoing non-linear regression of logistic growth in 136 countries, bi-polarization between ICT advanced countries and ICT growing countries in 146 countries including Myanmar and Laos is illustrated in Figure 11 and presented in Table 1. 
Sandar, K.

Watanabe, $\mathrm{C}$.
Looking at Figure 11 and Table 1 it is seen that 146 countries have spirit into 2 economies: (i) ICT growing 119 countries (nations with ranking from 28 to 146) have been enjoying a virtuous cycle between ICT advancement and its marginal productivity increases, and (ii) ICT advanced 27 countries (nations with ranking from 1 to 27) have fallen into a pit of a vicious cycle as ICT advancement decreases their marginal productivity.

Figure 11: Bi-polarization between ICT Advanced and ICT Growing countries in 146 countries (2012)

Table 1: ICT Advanced Countries and ICT Growing Countries in 2012

\begin{tabular}{|c|c|c|c|c|c|c|c|c|c|c|c|c|c|c|}
\hline 1 & Finland & 5.98 & 31 & Saudi Arabia & 4.82 & 61 & Slovak Republic & 3.95 & 91 & Ecuador & 3.58 & 121 & Gabon & 2.97 \\
\hline 2 & Singapore & 5.96 & 32 & Lithuania & 4.72 & 62 & Kuwait & 3.94 & 92 & Kenya & 3.54 & 122 & Mali & 2.97 \\
\hline 3 & Sweden & 5.91 & 33 & Portugal & 4.67 & 63 & Mexico & 3.93 & 93 & El Salvador & 3.53 & 123 & Benin & 2.97 \\
\hline 4 & Netherlands & 5.81 & 34 & Chile & 4.59 & 64 & Greece & 3.93 & 94 & Lebanon & 3.53 & 124 & Cameroon & 2.95 \\
\hline 5 & Norway & 5.66 & 35 & Cyprus & 4.59 & 65 & Georgia & 3.93 & 95 & Ghana & 3.51 & 125 & Nicaragua & 2.93 \\
\hline 6 & Switzerland & 5.66 & 36 & Puerto Rico & 4.55 & 66 & Colombia & 3.91 & 96 & Botswana & 3.50 & 126 & Nepal & 2.93 \\
\hline 7 & United Kingdom & 5.64 & 37 & Slovenia & 4.53 & 67 & FYR Macedonia & 3.89 & 97 & Liberia & 3.48 & 127 & Lao & 2.93 \\
\hline 8 & Denkmark & 5.58 & 38 & Spain & 4.51 & 68 & India & 3.88 & 98 & Gambia & 3.47 & 128 & Tanzania & 2.92 \\
\hline 9 & United States & 5.57 & 39 & Barbados & 4.49 & 69 & Sri Lanka & 3.88 & 99 & Argentina & 3.47 & 129 & Ethiopia & 2.85 \\
\hline 10 & Taiwan, China & 5.47 & 40 & Oman & 4.48 & 70 & South Africa & 3.87 & 100 & & 3.45 & 130 & Malawi & 2.83 \\
\hline 11 & Korea Rep & 5.46 & 41 & Lativa & 4.43 & 71 & Bulgaria & 3.87 & 101 & Islamic Republic of Iran & 3.43 & 131 & Burkina Faso & 2.80 \\
\hline 12 & Canada & 5.44 & 42 & Cazech Republic & 4.38 & 72 & Trinidad and Tobago & 3.87 & 102 & Guatemala & 3.42 & 132 & Algeria & 2.78 \\
\hline 13 & Germany & 5.43 & 43 & Kazakhstan & 4.32 & 73 & Ukarine & 3.87 & 103 & Peru & 3.39 & 133 & Libya & 2.77 \\
\hline 14 & Hong Kong & 5.40 & 44 & Hungary & 4.29 & 74 & Thailand & 3.86 & 104 & Paraguay & 3.37 & 134 & Mozambique & 2.76 \\
\hline 15 & Isreal & 5.39 & 45 & Turkey & 4.22 & 75 & Riom & 3.86 & 105 & Paki & 3.35 & 135 & Timor Leste & 2.72 \\
\hline 16 & Luxemburg & 5.37 & 46 & Panama & 4.22 & 76 & Indone & 3.84 & 106 & bodia & 3.34 & 136 & Mauritiania & 2.71 \\
\hline 17 & Iceland & 5.31 & 47 & Jordan & 4.20 & 77 & & 3.84 & 107 & & 3.33 & 137 & & 2.69 \\
\hline 18 & Australia & 5.26 & 48 & Montenegro & 4.20 & 78 & Bosnia and Herzegovina & 3.80 & 108 & Venezuela & 3.33 & 138 & Madagascar & 2.69 \\
\hline 19 & Austria & 5.25 & 49 & Poland & 4.19 & 79 & Sey & 3.80 & 109 & & 3.32 & 139 & Lesotho & 2.68 \\
\hline 20 & New Zeland & 5.2 & 50 & Italy & 4.18 & 80 & & 3.7 & 110 & & 3.30 & 140 & Mlyanmar & 2.67 \\
\hline 21 & Japan & 5.24 & 51 & Côte d'lvoire & 4.17 & 81 & Verde & 3.78 & 111 & & 3.29 & 141 & Yemen & 2.63 \\
\hline 22 & Estoni & & 52 & & 4.16 & 82 & & 3. & 112 & & 3.29 & 142 & Guinea & 2.61 \\
\hline 23 & Qatar & 5.10 & 53 & Cost & 4.15 & 83 & Alb & 3.75 & 113 & & 3.27 & 143 & & 2.58 \\
\hline 24 & Belgium & 5.10 & 54 & Federation & 4.13 & 84 & & 3.74 & 114 & adesh & 3.22 & 144 & Chad & 2.53 \\
\hline 25 & UAE & 5.07 & 55 & Mauritius & 4.12 & 85 & & 3.74 & 115 & Zambia & 3.19 & 145 & Sierra Leone & 2.53 \\
\hline 26 & France & 5.06 & 56 & Azerbaijan & 4.11 & 86 & Philippines & 3.73 & 116 & Zimbabwe & 3.17 & 146 & Burundi & 2.30 \\
\hline 27 & Ireland & 5.05 & 57 & Brunei Darussalam & 4.11 & 87 & Serbia & 3.70 & 117 & Suriname & 3.13 & & & \\
\hline 28 & Malta & 4.90 & 58 & China & 4.03 & 88 & & & 118 & yz Republic & 3.09 & & & \\
\hline 29 & Bahr & $4.8-1250$ & 59 & Mo & 4.01 & 89 & Morocco & & 119 & Bolivia & 3.01 & & & \\
\hline 30 & Malausia & 4.82 & 60 & Brazil & 3.97 & 90 & Dominican Republic & 3.62 & 120 & Côte d'lvoire & 3.00 & & & \\
\hline
\end{tabular}

27 countries with ICT advanced economies (vicious cycle) 119 countries with ICT growing economies (virtuous cycle) 


\section{MYANMAR'S POSSIBLE DEVELOPMENT TRAJECTORY}

\section{Assessment of Myanmar's State of ICT Driven Economic Development}

Utilizing the result of the identification of Myanmar's current ICT advancement level as NRI $=2.67$, on the basis of Rogers's diffusion theory (Rogers, 1962) and CHASM (Moore, 1991,1999), Myanmar's current state of development in the ICT driven economy and potential barrier to overcome for its autonomous development were assessed. Figure 12 illustrates the scheme of this assessment.
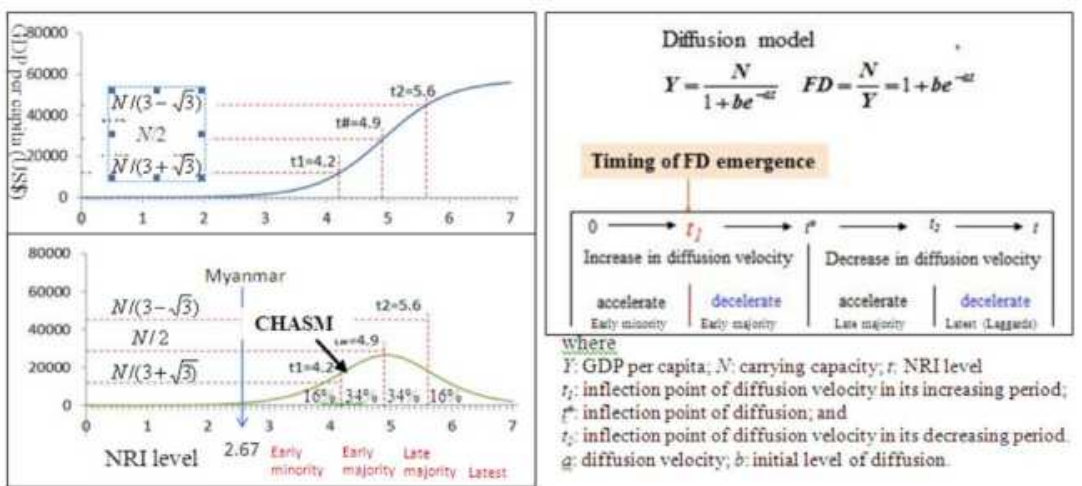

Figure 12: Trajectory of ICT Driven Development and Barrier to Overcome for Autonomous Development.

Sources: Rogers (1962), Moore (1991, 1999).]

Since Myanmar's current state of ICT advancement is estimated at NRI $=2.67$ and hence exists in the early minority stage, which is based on the analysis in the preceding section. As postulated by Moore (1991, 1999), it is indispensable to overcome CHASM for its autonomous development. This task corresponds to shifting from early minority stage to early majority stage as reviewed in the preceding section.

Figure 12 demonstrates that this shift can be enabled by developing ICT to a level which is higher than NRI $=4.2$ in the current global ICT driven economic development trajectory.

Therefore, given the current global ICT driven development trajectory, a possibility of Myanmar's economic development toward autonomous development depends on whether it can activate its latent institutional capacity in accelerating ICT advancement as from NRI 2.67 to 4.2 level by waking up from long lasting institutional stagnation.

\section{Effects of the Support for ICT Advancement - Governing Factors for ICT Advancement}

International Telecommunication Union (ITU) stressed that the advancement
Strategic Option of ICT Driven 
Sandar, K.

Watanabe, $\mathrm{C}$. of ICT has become decisive to nation's competitiveness (ITU, 2013) while WEF identified 11 pillars critical to global competitiveness as illustrated in Figure 13 (WEF, 2013a).

\section{Global Competitiveness Index}

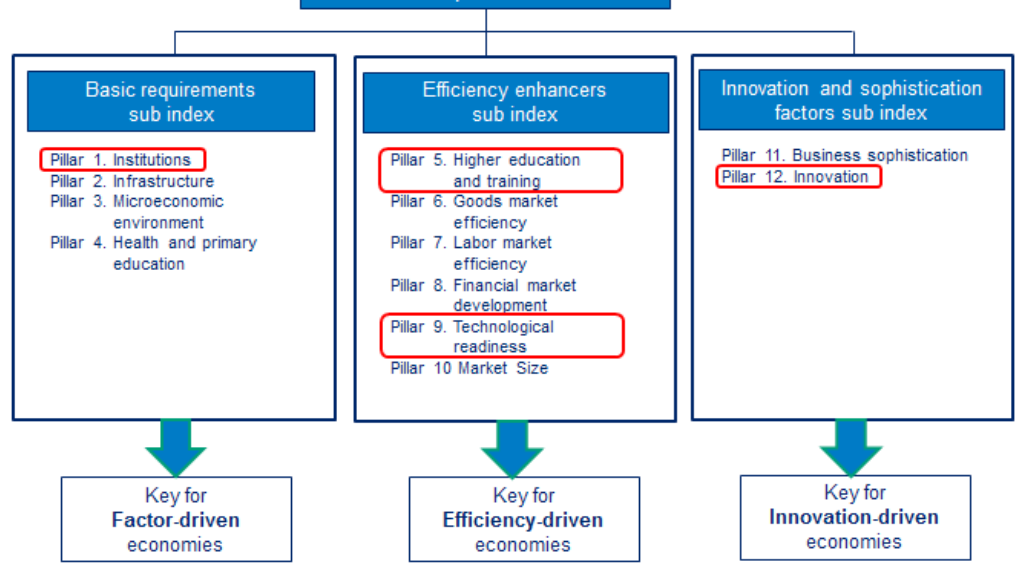

Figure 13: Critical Pillars for Global Competitiveness

Source: The Global Competitiveness Report 2013-2014 (WEF, 2013a).

These postulates suggest a possibility that the following four factors can be decisive to the level of NRI:

(i) Pillar 12 - Innovation,

(ii) Pillar 1- Institutions (Institutional environment determined by the legal and administrative framework within which individuals, firms, and gov ernments interact to generate wealth),

(iii) Pillar 5 - Higher education and training/ Internet access in school, and (iv) Pillar 9 - Technological readiness/Internet broadband subscriptions.

Table 2 demonstrates these factors in ASEAN 10 countries, China and India in 2012.

Table 2 Factors Decisive to ICT Advancement: ASEAN 10 Countries, China and India (2012)

\begin{tabular}{|c|c|c|c|c|c|c|c|c|c|c|c|c|}
\hline & \begin{tabular}{|l|} 
Singapore \\
\end{tabular} & China & Malaysia & Brunei & \begin{tabular}{|l|} 
Indonesia \\
\end{tabular} & Vietnam & India & Philippines & Thailand & Laos & \begin{tabular}{|l|} 
Cambodia \\
\end{tabular} & Myanmar \\
\hline Innovation & \begin{tabular}{|l|}
5.2 \\
\end{tabular} & 3.9 & 4.4 & 3.4 & 3.8 & 3.1 & 3.6 & \begin{tabular}{|l|}
3.2 \\
\end{tabular} & 3.2 & 3.2 & 3 & 2.2 \\
\hline Institutions & 6.00 & 4.20 & 4.80 & 5.00 & 4.00 & 3.50 & 3.90 & 3.80 & 3.80 & 4.00 & 3.60 & 2.80 \\
\hline Internet Access in School & 6.30 & 5.30 & 5.20 & 5.50 & 4.80 & 5.10 & 4.10 & 4.20 & 4.40 & 3.90 & 3.80 & 2.20 \\
\hline $\begin{array}{l}\text { Internet Broadband } \\
\text { Subscription }\end{array}$ & 56.73 & 14.95 & 10.65 & 6.04 & 6.19 & 9.75 & 2.32 & 2.89 & 0.79 & 1.10 & 1.17 & 1.00 \\
\hline
\end{tabular}

Source: The Global Competitiveness Report 2013-2014 (WEF, 2013a). 
With the foregoing review, level of NRI can be depicted by the following function:

$N R I=F(I N V, I N S, I A S, I B S)$

where,

$I N V$ : Innovation,

INS: Institutions,

$I A S$ : Internet access in school, and

$I B S$ : Internet broadband subscription

Taylor expansion to the first term,

$\ln N R I=a+b \ln I N V+c \ln I N S+d \ln I A S+e \ln I B S$

where $a, b, c, d$ and $e$ : coefficients.

Cross countries analysis for 51 countries (OECD 34, ASEAN 10, BRICS 5, Hong Kong and Taiwan) in 2012 is demonstrated in the following expression:

$$
\begin{aligned}
& \ln N R I=0.366+0.364 \ln I N V+0.225 \ln I N S+0.135 \ln I A S+0.036 \ln I B S \text { adj. } R^{2} 0.925 \\
& \text { (5.01) } \quad(5.59)
\end{aligned}
$$

Figures in parenthesis indicate t-value. All demonstrate significance at the $1 \%$ level. By applying respective governing factors as demonstrated in Table 2, Myanmar's NRI level in 2012 can be estimated as 2.65 which is almost equivalent to the preceding estimate by means of ICT driven logistic growth (2.67). It lies between the levels of Lesotho (2.68) and Yemen (2.63), which is same as the preceding estimate.

These analyses demonstrate that four factors as INV, INS, IAS and IBS are decisive to the advancement of ICT in 51 countries examined including Myanmar.

\section{Myanmar's Institutional Identity Supportive to Effective Utilization of ICT}

\section{Hofstede's 5 Cultural Dimensions}

As reviewed earlier, Hofstede (1991) examined institutional identity of the nations in the world and compared five cultural dimensions (power distance, individualism, masculinity, uncertainty avoidance and long term orientation) in major countries. Since, majority of the ASEAN countries are not included in his comparison or are not compared on equitable basis. On the basis of cross-country analysis governing institutional factors of each of the respective five dimensions in leading 19 countries identified (see Table A1 in Appendix III). These dimensions in 9 South East Asian countries (ASEAN countries excluding Brunei) estimated as demonstrated in Figure 14 (see details in Appendix III). Comparing national culture among 9 countries, Myanmar

Journal of Technology Management for Growing Economies, Volume 5, Number 2, October 2014
Strategic Option of ICT Driven 
Sandar, K.

Watanabe, $\mathrm{C}$. demonstrates the highest cultural value for long term orientation. It shows that people are looking forward to see the future development, have expectations towards changes, credits, rewards, and persistence and are ready for the next level of advancement.

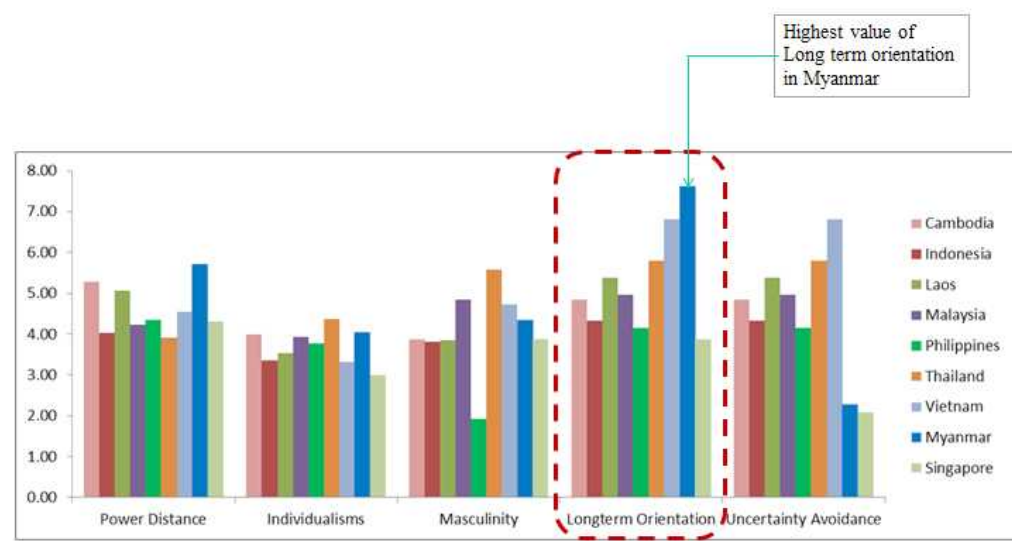

Figure 14: 5 Cultural Dimensions in 9 South East Asian Countries Sources: Authors' estimate based on "Cultures and Organizations" (Hofstede, 1991).

\section{Primary Education Enrollment}

Since, it is pointed out many times that ICT literacy education at the primary education state is essential for nation's ICT advancement (e.g., ITU, 2013), level of primary education enrollment plays a significant role for ICT growing nations to catch up. With this understanding, primary education enrollment level of the nations was compared. Figure 16 demonstrates world top 20 countries with respect to higher primary education enrollment in 2012.

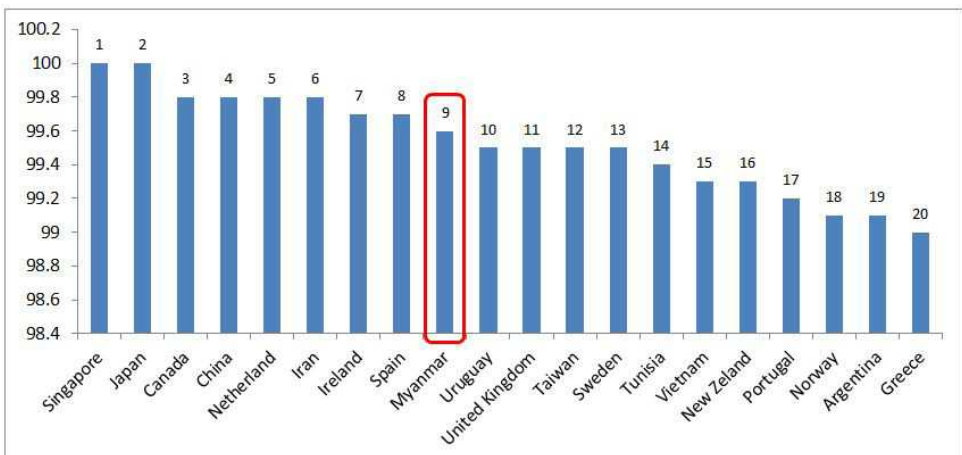

Figure 15: Primary Education Enrollment Level in World Top 20 countries (2012). Sources: The Global Competitiveness Report 2013-2014 (WEF, 2013a).

Looking at Figure 15, we note that Myanmar is in the $9^{\text {th }}$ position in the world in

Journal of Technology Management for Growing Economies, Volume 5, Number 2, October 2014 
terms of primary education enrollment rate. It shows that the primary educational level for Myanmar is the $2^{\text {nd }}$ top within ASEAN countries following Singapore. This suggests that Myanmar incorporates latent capacity in efficiently learning and absorbing external resources for innovation as experienced by Singapore (Chew et al., 2010).

Foregoing institutional identity as conspicuous long-term orientation and latent capacity for open innovation convinces of the possibility for Myanmar to construct ICT driven autonomous developing trajectory.

\section{Effects of ICT Support from ICT Advanced Countries to Myanmar's Devel- opment}

Based on the conspicuous economic growth of Myanmar during 1999 to 2007 was $11.16 \%$ p.a. as demonstrated in Figure 3 and foregoing institutional strength prompted the possibility of Myanmar's dramatic ICT advancement being sufficient enough for leading towards the autonomous development. This will be achieved by overcoming CHASM in a reasonable period once it undertakes priority strategy accelerating its open innovation.

As discussed under Analytical Framework, ICT driven logistic growth suggests the following epidemic function which can be transformed as follows:

$$
\begin{aligned}
& \frac{d Y}{d I}=a Y\left(1-\frac{Y}{N}\right) \\
& \frac{\frac{d Y}{d I}}{Y}=\frac{\frac{d Y}{d}}{Y} \cdot \frac{\frac{d I}{I}}{I} \cdot I=a\left(1-\frac{Y}{N}\right) \\
& \frac{\Delta I}{I}=\frac{\frac{\Delta Y}{Y}}{I \cdot a\left(1-\frac{Y}{N}\right)}
\end{aligned}
$$

where, $Y=V / P$ (GDP per capita), $I=N R I$ and $, \Delta Y=d Y / d t, \Delta I=d I / d t$ $N$ : carrying capacity, and $a$ : velocity of diffusion.

Given that Myanmar's accomplishment of $11.16 \%$ p.a. GDP increased during the period 1999-2007 (Fig. 2), under the current ICT driven global logistic growth, it is equivalent to $2 \%$ p.a. NRI increase.

This suggests that with the foregoing economic growth demonstrated in the period 1999-2007 supported by its take off strategy consisting of innovation, institutional change, higher education and technological readiness endeavor, CHASM can be overcome within 23 years by its own effort as $2.67(1+0.02)^{23}=4.20$.

However, if Myanmar effectively utilizes its external resources for ICT advancement based on its latent institutional strength, $2 \%$ p.a. NRI increase can move to $5 \%$ p.a. as a consequence of multiplier effect enabling it to overcome CHASM by 10 years as shown below $2.67(1+0.05)^{10}=4.35$.

Journal of Technology Management for Growing Economies, Volume 5, Number 2, October 2014
Strategic Option of ICT Driven 
Sandar, K.

Watanabe, $\mathrm{C}$.

This multiplier effect can be attributed to advancements of institutions (INS), Internet access in school (IAS) and Internet broadband subscription (IBS) effects. All of these can be expected by such policy initiatives as the take off strategy incorporating strong locomotives as institutional change, higher education and technological readiness endeavour.

Figure 16 illustrates these possible scenarios for Myanmar for its autonomous development trajectory by overcoming CHASM. Given that Myanmar's conspicuous economic growth in 1999-2007 can be attributed to NRI enhancement efforts, which is equitable to $5 \%$ p.a. increase, continued efforts to sustain such performance will enable Myanmar to overcome CHASM leading to autonomous development in 2022.
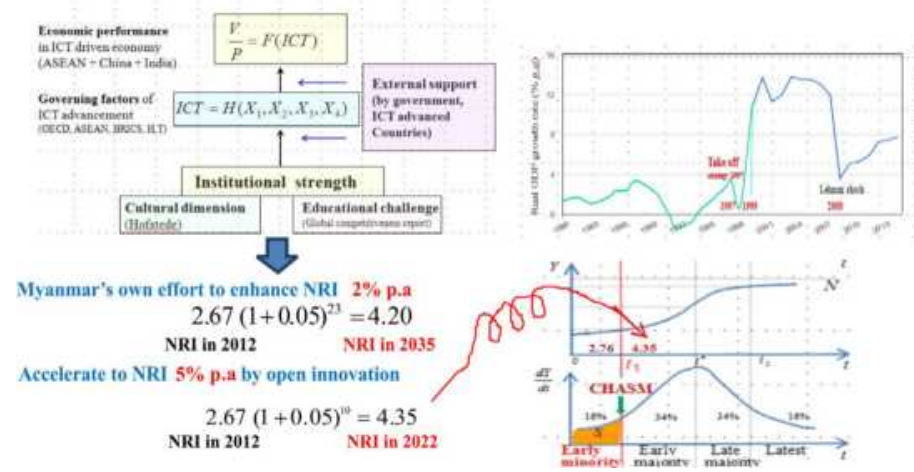

Figure 16: Effects of ICT Support to Myanmar from ICT Advanced Countries.

\section{Possible Scenario for Myanmar's ICT Driven Development Trajectories}

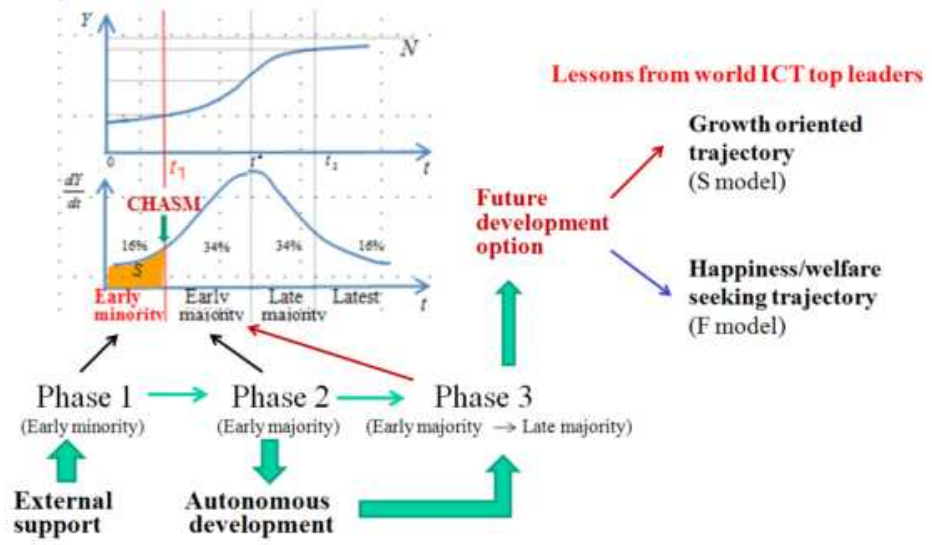

Figure 17: Possible Option between Growth Oriented or Happiness and Welfare Seeking

Journal of Technology Management for Growing Economies, Volume 5, Number 2, October 2014 
Foregoing assessment on the effects of ICT support from ICT advanced countries to Myanmar's development envisions possible options for Myanmar's future development as illustrated in Figure 17.

While, Myanmar currently is in the phase of early minority, it incorporates latent ability for effective utilization of advanced ICT. Therefore, with the support of advanced ICT from the external ICT advanced countries, the country can accelerate its development sufficient enough to overcome CHASM and can reach out to the next phase, early majority in that autonomous development can be expected.

Upon reaching to the level of advancement at the peak before entering into late majority phase by means of autonomous development, Myanmar has an option for its future development by following the path of ICT leaders. It can follow Singapore's model leading to growth oriented trajectory (S model) or Finland's model of leading to happiness and welfare seeking trajectory (F model) which are compared in Figure 6. These models in Singapore and Finland are crystals of respective institutional development with comparative advantage and disadvantage respectively. They are not a case of easy option but a formation of nation's DNA based on respective institutional systems. Thus, Myanmar's development strategy from current stage to post CHASM stage by utilizing ICT support from external ICT advanced nations should be carefully considered with long-term perspectives.

\section{CONCLUSION}

The current position of Myanmar in the global ICT vs per capita income development trajectory was estimated and identified. Based on the analysis of bi-polarization between ICT advanced countries (which suffer a vicious cycle between ICT advancement and its productivity increase) and growing countries (which enjoys a virtuous cycle between them), the significance of a co-evolutionary acclimatization that harnesses the vigor of emerging counterparts was identified. Myanmar has the position to anticipate support for its ICT advancement from ICT advanced countries in establishing a coevolutionary acclimatization. Utilizing the effects of these supports should be focused on governing factors to ICT advancement. In addition, it was found that Myanmar's institutional identity was supportive to effective utilization of ICT support. Lastly, based on the combined analysis of the similarity and disparity between world ICT top leaders, Finland and Singapore, Myanmar's strategic options to choose from were compared. The comparisons were based on the possible scenario for Myanmar's ICT driven development trajectories, viz., growth oriented or welfare and happiness seeking.

Journal of Technology Management for Growing Economies, Volume 5, Number 2, October 2014
Strategic Option of ICT Driven 


\section{Sandar, K. Noteworthy Findings}

Watanabe, C.

\section{ICT driven Development Trajectory}

(i) From the empirical analysis, all 146 countries follow the logistic growth.

(ii) Consequently, bi-polarization between ICT advanced countries and ICT growing countries become significant and critical since it identifies the current position of global ICT advancement level vs per capita income development trajectory.

(iii) This shows the significance of co-evolutionary acclimatization and how effective utilization of the ICT upon advanced countries becomes crucial for development strategy of ICT growing countries including Myanmar.

\section{Effects of the Support for ICT Advancement}

(i) For the advancement of ICT, it is required to utilize the ICT support effectively by the countries where ICT is on the rise such as Myanmar. It is governed primarily by innovation, institutions, education and technological readiness.

(ii) Myanmar's identity of institutional strength are in long term orientation, the foundation of primary education and based on the subsequent vitality in transforming strength into springboard for rapid or high economic growth.

(iii) Based on such a performance it can be anticipated that Myanmar could advance NRI increase to overcome CHASM leading to the autonomous development, from early minority to early majority within 10 years.

\section{Possible Scenario for Myanmar's ICT Development Trajectories}

(i) Upon shifting to the early majority phase, Myanmar autonomously explored economic development to late majority group. At such state, the future option for further development of the economic becomes critical.

(ii) In this context, the lessons learnt from ICT top leaders, which are in contrast with each other, the trajectory happiness and welfare seeking in Finland, and growth oriented in Singapore. This suggests the significance of future trajectory shaping for Myanmar.

(iii) Myanmar should carefully decide for future options at this point. Comparing with majority of the countries, Myanmar had suffered the economic downturn for many years and been in the stagnation stage for many decades. From past lessons, Myanmar should not neglect the growth orientation and continue for future development. Meanwhile, Myanmar

Journal of Technology Management for Growing Economies, Volume 5, Number 2, October 2014 
should take a balance interest on the happiness and welfare of its citizens.

\section{Policy Suggestions}

\section{ICT driven Development Trajectory}

(i) All nations should realize that their economic development trajectories are subject to the advancement of ICT in an ICT driven economy.

(ii) In this context, careful attention to the two faced nature of ICT should be paid.

(iii) Effective utilization of the support of ICT advancement from ICT advanced countries is essential for countries in the early minority in the development stage in overcoming CHASM leading to shifting to autonomous development trajectory.

\section{Effects of the Support for ICT Advancement}

(i) Given the significant role that ICT takes for nation's development, institutional factors governing ICT advancement should be fully realized.

(ii) Policies leveraging respective institutional strength inductive to indigenous ICT advancement as well as effective utilization of ICT support from ICT advanced countries should be prioritized.

(iii) Myanmar should endeavor to maximize its latent institutional strength in sustaining conspicuous economic growth demonstrated in the period 1999-2007, which can be considered equitable to $5 \%$ p.a. increase in NRI for overcoming CHASM within a decade by means of effective utilization of ICT support from ICT advanced countries.

\section{Possible Scenario for Myanmar's ICT Development Trajectories}

(i) Given the ICT driven economic development trajectory common to all countries, contrasting accomplishment observed in the world ICT top leaders, Finland and Singapore should be carefully examined.

(ii) Myanmar should best utilize its comparative advantage as a late comer to be able to maximize the effect of the lessons from preceding endeavor in ICT leaders for its indigenous ICT driven development trajectory shaping.

(iii) Stepwise option as a) best learning from growth oriented trajectory for its rapid advancement in overcoming CHASM, $b$ ) shaping hybrid trajectory fusing growth oriented and happiness/welfare seeking, and $c$ ) more emphasis on its identical happiness/welfare trajectory would be one of the practical option for Myanmar empowering all nations endeavor constructing a new country not only for its own but also for global

Journal of Technology Management for Growing Economies, Volume 5, Number 2, October 2014 
Sandar, K.

Watanabe, C.

community.

\section{Future Work}

(i) Further supplemental empirical analysis for Myanmar endorsing the equitability of "conspicuous economic development in 1999-2007" to 5\% p.a. NRI increase.

(ii) Road map for Myanmar's attainment of 5\% p.a. NRI increase.

(iii) Detailed scenario options envisioning Myanmar's option for its new country construction.

(iv) Similar analyses on countries in early minority and comparative assessment between these countries thereon.

\section{APPENDICES}

Appendix I: NRI Score and GDP per Capita in 146 Countries (2012)

\begin{tabular}{|l|c|c|c|}
\hline Country & NRI Score & NRI Rank & GDP per capita \\
\hline Finland & 5.98 & 1 & 45634.93 \\
\hline Singapore & 5.96 & 2 & 52051.81 \\
\hline Sweden & 5.91 & 3 & 54814.80 \\
\hline Netherlands & 5.81 & 4 & 46010.95 \\
\hline Norway & 5.66 & 5 & 99170.20 \\
\hline Switzerland & 5.66 & 6 & 78880.93 \\
\hline United Kingdom & 5.64 & 7 & 39160.58 \\
\hline Denmark & 5.58 & 8 & 56426.45 \\
\hline United States & 5.57 & 9 & 51703.95 \\
\hline Taiwan, China & 5.47 & 10 & 20335.92 \\
\hline Korea Rep & 5.46 & 11 & 22588.92 \\
\hline Canada & 5.44 & 12 & 52299.76 \\
\hline Germany & 5.43 & 13 & 41865.52 \\
\hline Hong Kong & 5.40 & 14 & 36676.30 \\
\hline Israel & 5.39 & 15 & 33432.68 \\
\hline Luxemburg & 5.37 & 16 & 106406.42 \\
\hline Iceland & 5.31 & 17 & 42725.04 \\
\hline Australia & 5.26 & 18 & 67304.47 \\
\hline Austria & 5.25 & 19 & 46642.88 \\
\hline New Zealand & 5.25 & 20 & 38254.62 \\
\hline
\end{tabular}

Journal of Technology Management for Growing Economies, Volume 5, Number 2, October 2014 


\begin{tabular}{|c|c|c|c|}
\hline Country & NRI Score & NRI Bank & GDP per capita \\
\hline Japan & 5.24 & 21 & 46706.72 \\
\hline Estonia & 5.12 & 22 & 16720.16 \\
\hline Qatar & 5.10 & 23 & 104755.81 \\
\hline Belgium & 5.10 & 24 & 43615.17 \\
\hline UAE & 5.07 & 25 & 43773.84 \\
\hline France & 5.06 & 26 & 41223.31 \\
\hline Ireland & 5.05 & 27 & 45984.37 \\
\hline Malta & 4.90 & 28 & 20998.40 \\
\hline Bahrain & 4.83 & 29 & 23554.76 \\
\hline Malaysia & 4.82 & 30 & 10344.87 \\
\hline Saudi Arabia & 4.82 & 31 & 24523.92 \\
\hline Lithuania & 4.72 & 32 & 14009.01 \\
\hline Portugal & 4.67 & 33 & 20037.74 \\
\hline Chile & 4.59 & 34 & 15410.12 \\
\hline Cyprus & 4.59 & 35 & 26388.99 \\
\hline Puerto Rico & 4.55 & 36 & 27500.20 \\
\hline Slovenia & 4.53 & 37 & 22100.12 \\
\hline Spain & 4.51 & 38 & 28670.09 \\
\hline Barbados & 4.49 & 39 & 15198.72 \\
\hline Oman & 4.48 & 40 & 25356.14 \\
\hline Latvia & 4.43 & 41 & 13899.89 \\
\hline Czech Republic & 4.38 & 42 & 18624.30 \\
\hline Kazakhstan & 4.32 & 43 & 11983.03 \\
\hline Hungary & 4.29 & 44 & 12652.04 \\
\hline Turkey & 4.22 & 45 & 10526.80 \\
\hline Panama & 4.22 & 46 & 9918.73 \\
\hline Jordan & 4.20 & 47 & 4878.78 \\
\hline Montenegro & 4.20 & 48 & 6777.56 \\
\hline Poland & 4.19 & 49 & 12709.27 \\
\hline Italy & 4.18 & 50 & 33115.01 \\
\hline Côte d'Ivoire & 4.17 & 51 & 12829.45 \\
\hline Uruguay & 4.16 & 52 & 14766.83 \\
\hline Costa Rica & 4.15 & 53 & 9665.03 \\
\hline
\end{tabular}

Strategic Option of ICT Driven 
Sandar, K.

Watanabe, C.

\begin{tabular}{|l|c|c|c|}
\hline Country & NRI Score & NRI Bank & GDP per capita \\
\hline Russian Federation & 4.13 & 54 & 14302.09 \\
\hline Mauritius & 4.12 & 55 & 8850.17 \\
\hline Azerbaijan & 4.11 & 56 & 7450.24 \\
\hline Brunei Darussalam & 4.11 & 57 & 42402.38 \\
\hline China & 4.03 & 58 & 6071.47 \\
\hline Mongolia & 4.01 & 59 & 3627.20 \\
\hline Brazil & 3.97 & 60 & 11358.54 \\
\hline Slovak Republic & 3.95 & 61 & 17007.84 \\
\hline Kuwait & 3.94 & 62 & 48761.24 \\
\hline Mexico & 3.93 & 63 & 10058.50 \\
\hline Greece & 3.93 & 64 & 22072.45 \\
\hline Georgia & 3.93 & 65 & 3519.59 \\
\hline Colombia & 3.91 & 66 & 7919.17 \\
\hline FYR Macedonia & 3.89 & 67 & 4660.05 \\
\hline India & 3.88 & 68 & 1500.76 \\
\hline Sri Lanka & 3.88 & 69 & 2875.80 \\
\hline South Africa & 3.87 & 70 & 7525.39 \\
\hline Bulgaria & 3.87 & 71 & 7006.25 \\
\hline Trinidad and Tobago & 3.87 & 72 & 19373.22 \\
\hline Ukraine & 3.87 & 73 & 3877.28 \\
\hline Thailand & 3.86 & 74 & 5390.41 \\
\hline Romania & 3.86 & 75 & 7939.30 \\
\hline Indonesia & 3.84 & 76 & 3593.67 \\
\hline Moldova & 3.84 & 77 & 2037.35 \\
\hline Bosnia and Herze- & & & \\
govina & 3.80 & 78 & 4461.17 \\
\hline Seychelles & 3.80 & 79 & 11240.42 \\
\hline Egypt & 3.78 & 80 & 3111.87 \\
\hline Cape Verde & 3.78 & 81 & 3686.75 \\
\hline Armenia & 3.76 & 82 & 3020.58 \\
\hline Albania & 3.75 & 83 & 3870.34 \\
\hline Vietnam & 3.74 & 84 & 1752.62 \\
\hline Jamaica & 3.74 & 85 & 5358.30 \\
\hline Philippines & 86 & 2611.50 \\
\hline & & & \\
\hline
\end{tabular}




\begin{tabular}{|l|c|c|c|}
\hline Country & NRI Score & NRI Bank & GDP per capita \\
\hline Serbia & 3.70 & 87 & 5309.36 \\
\hline Rwanda & 3.68 & 88 & 681.52 \\
\hline Morocco & 3.64 & 89 & 2955.86 \\
\hline Dominican Republic & 3.62 & 90 & 5766.16 \\
\hline Ecuador & 3.58 & 91 & 5742.65 \\
\hline Kenya & 3.54 & 92 & 966.59 \\
\hline El Salvador & 3.53 & 93 & 3788.00 \\
\hline Lebanon & 3.53 & 94 & 10310.65 \\
\hline Ghana & 3.51 & 95 & 1622.24 \\
\hline Botswana & 3.50 & 96 & 7020.12 \\
\hline Liberia & 3.48 & 97 & 435.96 \\
\hline Gambia & 3.47 & 98 & 497.30 \\
\hline Argentina & 3.47 & 99 & 11582.48 \\
\hline Guyana & 3.45 & 100 & 3647.06 \\
\hline Islamic Republic of Iran & 3.43 & 101 & 7207.19 \\
\hline Guatemala & 3.42 & 102 & 3325.68 \\
\hline Peru & 3.39 & 103 & 6525.36 \\
\hline Paraguay & 3.37 & 104 & 3903.66 \\
\hline Pakistan & 3.35 & 105 & 1260.74 \\
\hline Cambodia & 3.34 & 106 & 925.52 \\
\hline Senegal & 3.33 & 107 & 1074.10 \\
\hline Venezuela & 3.33 & 108 & 12917.52 \\
\hline Honduras & 3.32 & 109 & 2331.15 \\
\hline Uganda & 3.30 & 110 & 595.90 \\
\hline Namibia & 3.29 & 111 & 6063.85 \\
\hline Tajikistan & 3.29 & 112 & 953.32 \\
\hline Nigeria & 3.27 & 113 & 1640.11 \\
\hline Bangladesh & 3.22 & 114 & 797.16 \\
\hline Zambia & 3.19 & 115 & 1462.90 \\
\hline Zimbabwe & 3.17 & 116 & 755.55 \\
\hline Suriname & 3.13 & 117 & 8716.97 \\
\hline Kyrgyz Republic & 3.09 & 118 & 1158.47 \\
\hline Bolivia & 3.01 & 119 & 2514.32 \\
\hline
\end{tabular}

Strategic Option of ICT Driven 
Sandar, K.

Watanabe, $\mathrm{C}$.

\begin{tabular}{|l|c|c|c|}
\hline Country & NRI Score & NRI Bank & GDP per capita \\
\hline Côte d'Ivoire & 3.00 & 120 & 1057.26 \\
\hline Gabon & 2.97 & 121 & 11942.20 \\
\hline Mali & 2.97 & 122 & 631.31 \\
\hline Benin & 2.97 & 123 & 752.72 \\
\hline Cameroon & 2.95 & 124 & 1181.30 \\
\hline Nicaragua & 2.93 & 125 & 1733.13 \\
\hline Nepal & 2.93 & 126 & 690.04 \\
\hline Laos & 2.93 & 127 & 1379.90 \\
\hline Tanzania & 2.92 & 128 & 628.71 \\
\hline Ethiopia & 2.85 & 129 & 490.00 \\
\hline Malawi & 2.83 & 130 & 250.95 \\
\hline Burkina Faso & 2.80 & 131 & 635.77 \\
\hline Algeria & 2.78 & 132 & 5582.85 \\
\hline Libya & 2.77 & 133 & 12777.78 \\
\hline Mozambique & 2.76 & 134 & 634.25 \\
\hline Timor Leste & 2.72 & 135 & 5463.31 \\
\hline Mauritania & 2.71 & 136 & 1085.69 \\
\hline Swaziland & 2.69 & 137 & 3474.54 \\
\hline Madagascar & 2.69 & 138 & 451.48 \\
\hline Lesotho & 2.68 & 139 & 1294.28 \\
\hline Myanmar & 2.67 & 140 & 868.09 \\
\hline Yemen & 2.63 & 141 & 1366.93 \\
\hline Guinea & 2.61 & 142 & 518.89 \\
\hline Haiti & 2.58 & 143 & 758.85 \\
\hline Chad & 2.53 & 144 & 1201.14 \\
\hline Sierra Leone & 2.53 & 145 & 615.50 \\
\hline Burundi & 146 & 281.76 \\
\hline Soures: & & & \\
\hline
\end{tabular}

Sources: The Global Information Technology Report 2013 (World Economic Forum, 2013b) and World Economic Outlook Database (IMF, 2013). NRI in Myanmar and Laos are authors' estimate.

\section{Appendix II: Cultural Dimensions of the Nation}

Power Distance Index (PDI) that is the extent to which the less powerful members of organizations and institutions (like the family) accept and expect that power is distributed unequally. This represents inequality (more versus 
less), but defined from below, not from above. It suggests that a society's level of inequality is endorsed by the followers as much as by the leaders. Power and inequality, of course, are extremely fundamental facts of any society and anybody with some international experience will be aware that 'all societies are unequal, but some are more unequal than others'.

Individualism (IDV) on the one side versus its opposite, collectivism, that is the degree to which individuals are inte-grated into groups. On the individualist side we find societies in which the ties between individuals are loose: everyone is expected to look after him/herself and his/her immediate family. On the collectivist side, we find societies in which people from birth onwards are integrated into strong, cohesive in-groups, often extended families (with uncles, aunts and grandparents) which continue protecting them in exchange for unquestioning loyalty. The word 'collectivism' in this sense has no political meaning: it refers to the group, not to the state. Again, the issue addressed by this dimension is an extremely fundamental one, regarding all societies in the world.

Masculinity (MAS) versus its opposite, femininity refers to the distribution of roles between the genders which is another fundamental issue for any society to which a range of solutions are found. The IBM studies revealed that (a) women's values differ less among societies than men's values; (b) men's values from one country to another contain a dimension from very assertive and competitive and maximally different from women's values on the one side, to modest and caring and similar to women's values on the other. The assertive pole has been called 'masculine' and the modest, caring pole 'feminine'. The women in feminine countries have the same modest, caring values as the men; in the masculine countries they are somewhat assertive and competitive, but not as much as the men, so that these countries show a gap between men's values and women's values.

Uncertainty Avoidance Index (UAI) deals with a society's tolerance for uncertainty and ambiguity; it ultimately refers to man's search for Truth. It indicates to what extent a culture programs its members to feel either uncomfortable or comfortable in unstructured situations. Unstructured situations are novel, unknown, surprising, different from usual. Uncertainty avoiding cultures try to minimize the possibility of such situations by strict laws and rules, safety and security measures, and on the philosophical and religious level by a belief in absolute Truth; 'there can only be one Truth and we have it'. People in uncertainty avoiding countries are also more emotional, and motivated by inner nervous energy. The opposite type, uncertainty accepting cultures, are more tolerant of opinions different from what they are used to; they try to have as few rules as possible, and on the philosophical and
Strategic Option of ICT Driven 
Sandar, K.

Watanabe, C. religious level they are relativist and allow many currents to flow side by side. People within these cultures are more phlegmatic and contemplative, and not expected by their environment to express emotions.

Long-Term Orientation (LTO) versus short-term orientation: this fifth dimension was found in a study among students in 23 countries around the world, using a questionnaire designed by Chinese scholars It can be said to deal with Virtue regardless of Truth. Values associated with Long Term Orientation are thrift and perseverance; values associated with Short Term Orientation are respect for tradition, fulfilling social obligations, and protecting one's 'face'. Both the positively and the negatively rated values of this dimension are found in the teachings of Confucius, the most influential Chinese philosopher who lived around 500 B.C.; however, the dimension also applies to countries without a Confucian heritage.

Source: Hofstede (1991)

Appendix III: Analysis on Hofstede's Dimensions of National Cultures AIII.1. Five Dimensions of National Cultures in 19 Countries

Table A1: Five Dimensions of National Cultures in 19 Countries

\begin{tabular}{|c|c|c|c|c|c|}
\hline & Power Distance & Individualisms & Masculinity & $\begin{array}{c}\text { Uncertainty } \\
\text { Avoidance }\end{array}$ & $\begin{array}{c}\text { Long term } \\
\text { Orientation }\end{array}$ \\
\hline Australia & 3.58 & 4.50 & 4.11 & 3.93 & 3.43 \\
\hline Canada & 3.66 & 4.38 & 3.95 & 3.87 & 4.11 \\
\hline China & 4.38 & 3.00 & 4.19 & 3.40 & 4.77 \\
\hline Denmak & 2.89 & 4.30 & 2.77 & 3.14 & 3.83 \\
\hline Finland & 3.50 & 4.14 & 3.26 & 4.08 & 3.71 \\
\hline France & 4.22 & 4.26 & 3.76 & 4.45 & 3.66 \\
\hline Germany & 3.56 & 4.20 & 4.19 & 4.17 & 3.43 \\
\hline India & 4.34 & 3.87 & 4.03 & 3.69 & 4.11 \\
\hline Italy & 3.91 & 4.33 & 4.25 & 4.32 & 3.53 \\
\hline Japan & 3.99 & 3.83 & 4.55 & 4.52 & 4.38 \\
\hline Netherland & 3.64 & 4.38 & 2.64 & 3.97 & 3.78 \\
\hline New Zealand & 3.09 & 4.37 & 4.06 & 3.89 & 3.40 \\
\hline Norway & 3.43 & 4.23 & 2.08 & 3.91 & 3.78 \\
\hline Singapopre & 4.30 & 3.00 & 3.87 & 2.08 & 3.87 \\
\hline South Korea & 4.09 & 2.89 & 3.66 & 4.44 & 4.32 \\
\hline Sweden & 3.43 & 4.26 & 1.61 & 3.37 & 3.00 \\
\hline Switzerland & 3.53 & 4.22 & 4.25 & 4.06 & 3.69 \\
\hline United Kingdom & 3.56 & 4.49 & 4.19 & 3.56 & 3.22 \\
\hline United Sates & 3.69 & 4.51 & 4.13 & 3.83 & 3.37 \\
\hline
\end{tabular}

Source: Hofstede (1991)

Journal of Technology Management for Growing Economies, Volume 5, Number 2, October 2014 


\section{AIII.2. Governing Factors of Five Dimensions in 19 Countries}

(i) Power Dimension of ICT Driven

$P D=F(H E T, A O F, I S F, I N F, G I C, T P U)$

where

PD: Power dimension,

HET: Higher education and training,

$A C F$ : Access to financing,

ISF: Inadequately supply of infrastructure,

INF: Inflation,

GIC: Government instability or coups, and

TPU: Total population.

Taylor expansion to the first term,

$\ln P D=a+b \ln H E T+c \ln A C F+d \ln T P U+e \ln G I C+f \ln I N F+g \ln I S F$

where, $a, b, c, d$, e, fand $g$ : coefficients.

Cross countries analysis taking 19 countries in 2012 demonstrates as follows:

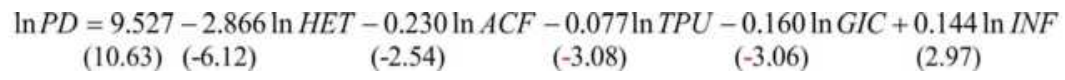

$-0.194 \ln I S F$ adj. $R^{2} 0.777$ $(-3.65)$

Figures in parenthesis indicate $\mathrm{t}$-value, all demonstrate significant at the $1 \%$ level.

Using multi-linear regression formula above and by applying respective significant factors, power dimension of Myanmar and other ASEAN countries (2012) can be estimated.

(ii) Individualisms

$\mathrm{IND}=\mathrm{F}(\mathrm{INC}, \mathrm{INF}, \mathrm{V} / \mathrm{P}, \mathrm{HDI})$

where,

IND: Individualisms,

INC: Income,

INF: Inflation,

V/P: GDP per capita, and

HDI: Human development index.

Taylor expansion to the first term, $\ln I N D=a+b \ln I N C+c \ln I N F+d \ln V / P+e \ln H D I$ 
Sandar, K.

Watanabe, C.

where $a, b, c$, and $e$ : coefficients.

Cross countries analysis taking 19 countries in 2012 demonstrates as follows:

$$
\begin{aligned}
& \ln I N D=-9.217+2.110 \ln I N C-0.320 \ln I N F-0.845 \ln V / P-5.280 \ln H D I \text { adj. } R^{2} 0.761 \\
& \begin{array}{llll}
(-2.45) & (5.29) \quad(-5.24) & (-2.96) & (-2.70)
\end{array}
\end{aligned}
$$

Figures in parenthesis indicate t-value, all demonstrate significant at the $1 \%$ level.

Using multi-linear regression formula above and by applying respective significant factors, Individualisms of Myanmar and other ASEAN countries (2012) can be estimated.

(iii) Masculinity

$\mathrm{MAS}=\mathrm{F}(\mathrm{INF}, \mathrm{TRD}, \mathrm{RLR}, \mathrm{ACF})$

where,

MAS: Masculinity,

INF: Inflation,

TRD: Technological readiness,

RLR: Restrictive labor regulations, and

ACF: Access to financing.

Taylor expansion to the first term,

$\ln M A S=a+b \ln I N F+c \ln T R D+d \ln R L R+e \ln A C F$

where, $a, b, c$, and $e$ : coefficients.

Cross countries analysis taking 19 countries in 2012 demonstrates as follows:

$$
\begin{aligned}
& \ln M A S=1.273+6.666 \ln I N C-3.554 \ln T R D-0.785 \ln R L R-0.487 \ln A C F \text { adj. } R^{2} 0.589 \\
& \begin{array}{llll}
(0.76) \quad(3.91) \quad(-2.52) & (-2.49) \quad(-2.32)
\end{array}
\end{aligned}
$$

Figures in parenthesis indicate t-value, all demonstrate significant at the $1 \%$ level.

Using multi-linear regression formula above and by applying respective significant factors, Masculinity of Myanmar and other ASEAN countries (2012) can be estimated.

(iv) Uncertainty Avoidance

$\mathrm{UAV}=\mathrm{F}(\mathrm{HET}, \mathrm{GME}, \mathrm{IGB}, \mathrm{PIN}, \mathrm{WEN}, \mathrm{PPH}, \mathrm{TXR}, \mathrm{ICI})$

where,

$U A V$ : Uncertainty avoidance,

HET: Higher education and training,

GME: Goods market efficiency,

IGB: Inefficient government bureaucracy,

Journal of Technology Management for Growing Economies, Volume 5, Number 2, October 2014 
PIN: Policy Instability,

WEN: Poor Work ethic in national labor force,

PPH: Poor public health,

TXR: Tax rates, and

ICI: Insufficient capacity to innovate.

Taylor expansion to the first term,

$\ln U A V=a+b \ln H E T+c \ln G M E+d \ln I G B+e \ln P I N+f \ln W E N+g \ln P P H+h \ln T X R+i \ln I C I$
Strategic Option of ICT Driven

where, $a, b, c, d, e, f, g, h$ and $i$ : coefficients.

Cross countries analysis taking 19 countries in 2012 demonstrates as follows:

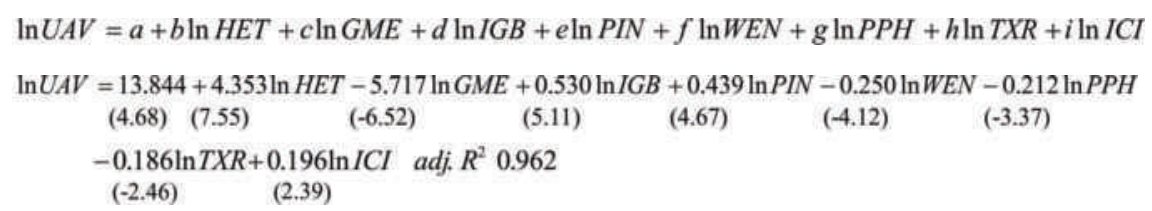

Figures in parenthesis indicate $t$-value, all demonstrate significant at the $1 \%$ level.

Using multi-linear regression formula above and by applying respective significant factors, Uncertainty Avoidance of Myanmar and other ASEAN countries (2012) can be estimated.

(v) Long Term Orientation

$L T O=F(G M E, I S F, G I C, P P H, A L T, H E T, B S P, H P I)$

where,

LTO: Longterm orientation,

GME: Goods market efficiency,

ISF: Inadequate supply of infrastructure,

GIC: Government instability or coups,

PPH: Poor public health,

ALT: Availability of latest technology,

HET: Higher education and training,

BSP: Business sophistication, and

HPI: Happiness index.

Taylor expansion to the first term, $\ln L T O=a+b \ln G M E+c \ln I S F+d \ln G I C+e \ln P P H+f \ln A L T+g \ln H E T+h \ln B S P+i \ln H P I$

where, $a, b, c, d, e, f, g, h$ and $i$ : coefficients.

$\ln U A V=2.380+6.982 \ln G M E-0.417 \ln I S F+0.182 \ln G I C-0.300 \ln P P H-2.982 \ln A L T-2.486 \ln H E T$

$\begin{array}{rrr}(0.90)(5.41) & (-5.25) & (3.95 \\ -2.672 & \ln B S P+1.259 \ln H P I & \text { adj. } R^{2} \\ 0.795\end{array}$

$(-2.39) \quad(2.36)$

Journal of Technology Management for Growing Economies, Volume 5, Number 2, October 2014 
Sandar, K.

Watanabe, C.
Figures in parenthesis indicate t-value, all demonstrate significant at the $1 \%$ level.

Using multi-linear regression formula above and by applying respective significant factors, Long Term Orientation of Myanmar and other ASEAN countries (2012) can be estimated.

Sources of the data for explanatory factors for each respective five dimensions are from the Global Competitiveness Report 2013-2014 (WEF, 2013a) and GDP per capita data from World Economic Outlook Database 2013. (IMF, 2013).

\section{ENDNOTES}

1. $S=\int_{0}^{t_{1}} \frac{d Y}{d t} d S=[Y]_{0}=\left[\frac{N}{1+b e^{-a t}}\right]_{0}^{t_{1}}=N\left[\frac{1}{3+\sqrt{3}}-\frac{1}{1+b}\right]$

where, S: whole production outcome in the period of the early minority (innovators + early adopters).

Given the initial level of diffusion $\mathrm{N} /(1+\mathrm{b})=0.05, \mathrm{~S} / \mathrm{N}=0.16$ and equivalent to the foregoing timing.

2. While, foregoing non-linear regression of logistic growth focused on 136 countries, not including 8 "abnormal countries" neither Myanmar nor Lao. With understanding that estimated logistic growth and subsequent bipolarization growth trajectory represent standardized trajectory, Figure 11 plotted these 10 countries based on their NRI and GDP per capita level.

3. The number of primary school students in 2011 was approximately $8 \%$, around 5.2 million of total population about 60 million. Those are public schools, private schools and religious-run schools. The number of State-run schools called public schools is over 41,000 in the whole country. As the land area of Myanmar is just over 677,000 sq. km, the farthest distance from home to school is about $2 \mathrm{~km}$ on average. At this moment, there are about 185,000 primary school teachers and as a result the overall teacher-student ratio is 1:29. Myanmar has laid down the policy of compulsory primary education in order to achieve $100 \%$ enrollment of students to enable them to acquire a basic education. To have a better education environment, not only public schools but also private and religious-run schools are playing in an active role. According to 2010 statistics, the literacy rate in Myanmar has 92\% which is higher than some South East Asian countries.

In Myanmar, religious-run schools still have a significant role in its education system. These schools play an important part in terms of access to education. They offer free education and especially target orphans or children from poor families who cannot afford to pursue formal education. They follow the official primary curriculum. These schools supervised by the Buddhist monks are very significant.

Journal of Technology Management for Growing Economies, Volume 5, Number 2, October 2014 
Source: Thu Hein Kyaw, Primary Education in Myanmar, http://www.accent.ac.nz/ elto/articles/primary-education-myanmar. Retrieved 6 July 2014.

4.

Population increase rate $\frac{\Delta P}{P}=2.0 \%$ p.a. (2010-2019; IMF, 2014), $I=2.67$ (2012), $a\left(1-\frac{Y}{N}\right)$

$=1.86(1-868 / 57206)=1.83(2012$, see $3(1))$.

$$
\frac{\Delta V}{I}=\frac{\frac{\Delta V}{T}}{I \cdot a\left(1-\frac{Y}{N}\right)}=\frac{11.16-2.00}{2.67 \times 1.83}=1.87 \% \approx 2 \%
$$

5. Myanmar's NRI can be depicted by the following function (see 4 (2))

$\ln N R I=0.366+0.364 \ln I N V+0.225 \ln I N S+0.135 \ln L A S+0.036 \ln I B S$

Since innovation is induced by ICT in ICT driven development, innovation can be depicted as follows:

$\ln I N V=a+b \ln N R I$

$\ln I N V=-0.372+1.15 \ln N R I$ adj. $R^{2} 0.819$

Synchronizing two equations

$\ln N R I=\frac{0.366+0.364 a}{1-0.364 b}+\frac{0.225}{1-0.364 b} \cdot \ln I N S+\frac{0.135}{1-0.364 b} \cdot \ln L 4 S+\frac{0.036}{1-0.364 b} \cdot \ln I B S$

$\ln N R I=0.397+0.387 \cdot \ln I N S+0.232 \cdot \ln L A S+0.062 \cdot \ln I B S$

$\frac{\Delta N R I}{N R I}=0.387 \frac{\Delta I N S}{I N S}+0.232 \frac{\Delta L A S}{L A S}+0.062 \frac{\Delta I B S}{I B S}=0.387 \times 7 \%+0.232 \times 10 \%+0.062 \times 10 \%=5.09 \%$

Growth rate of INS, IAS and IBS depend on Burke (2013), MCPT (2011) and Han (2010).

\section{REFERENCES}

Burke, A. (2013) 'Myanmar and Foreign Aid - Recent Changes, Risk and Opportunity.', The Policy Practice, September 2013, (online) (cited 6 July 2014) Available from $<$ URL:www.thepolicypractice.com.

Chew, M., Watanabe, C. and Toy, Y. (2010) 'Technology Leapfrogging: Findings from Singapore's Water Industry', Journal of Technology Management for Growing Economies, 1:2pp. 29-47.

Cowen, T.(2011) 'The Great Stagnation', New York. Dutton.

EU (2010) 'Europe 2020: A Strategy for Smart, Sustainable and Inclusive Growth.' Brussels. EU.

Evans, P. (2013) 'Competition Arrives in Myanmar's Restructured Telecom Sector: What Next? Myanmar (Burma) Telecoms, Mobile and Internet'19 ${ }^{\text {th }}$ Edition. (online) (cited 6 July 2014) Available from <URL: www.budde.com.au/Research/Myanmar-BurmaTelecom-Mobile-and-Internet.html $>$

Han, S.W.(2010) ICT Development in Myanmar by Department of Communication and Integrated Systems, Tokyo Institute of Technology, Cooperation Opportunities in ICT between Japan and Myanmar, Tokyo.

Hofstede, G. (1991) 'Cultures and Organizations', London. McGraw-Hill International.

ILO (2012) Distribution of Household Income by Source, ILO, Geneva.

International Monetary Fund (IMF), annual issues. World Economic Outlook Database. IMF, Washington.

International Telecommunication Union (ITU) (2013) Measuring the Information Society
Strategic Option of ICT Driven 
Sandar, K.

Watanabe, $\mathrm{C}$.
2013, ITU, Geneva.

Kyaw, T. H. 'Primary Education in Myanmar,' (online) (cited 6 July 2014) Available from <URL: http://www.accent.ac.nz/elto/articles/primary-education-myanmar>.

Kyi, K. M., Findlay, R. Sundrum, R.M., Maung, M., Nyunt, M. and Oo, Z. (2000) A Vision and a Strategy: Economic Development of Burma, Stockholm, The Olof International Center.

Mahajan, V., Muller, E. and Srivastava, R. K. (1990) 'Determination of Adopter Categories by Using Innovation Diffusion Models', Journal of Marketing Research, 27:1, pp. 3750.

Ministry of Communication Posts and Telegraphs (MCPT) (2011) Myanmar ICT Master Plan, MCPT, Yangon.

Moore, G.A. (1991) 'Crossing the Chasm, Marketing and Selling Technology Products to Mainstream Customers.', New York. Harper Business Essentials, Harper Collins.

Moore, G.A. (1999) 'Crossing the Chasm, Marketing and Selling Technology Products to Mainstream Customers.', New York. Harper Business Essentials, Harper Collins.

Rogers, E.M. (1962) 'The Diffusion of Innovations', ( $3^{r d} E d$.) New York. The Free Press of Glencoe.

Oo, T. (2012) Cooperation Opportunities in ICT between Japan and Myanmar. Myanmar Computer Federation, Myanmar Info-Tech, Yangon.

Tokumasu, S. and Watanabe, C. (2008) 'Institutional Structure Leading to the Similarity and Disparity in Innovation Inducement in EU 15 Countries.', Journal of Services Research, 8:1, pp. 5-42.

UN (2012) World Happiness Report, UN, New York.

UNDP (2013) Impact Assessment of the UNDP Human Development Initiative in Myanmar, UNDP, New York.

Watanabe, C. (2009) 'Co-evolutionary Dynamism between Innovation and Institutional Systems: The Rise and Fall of the Japanese System of Management of Technology', in The Science of Institutional Management of Technology: Elucidation of Japan's Indigenous Co-evolutionary Dynamism and Its Accrual to Global Assets. Tokyo. Tokyo Institute of Technology, pp. 21-34.

Watanabe, C. (2013) 'Innovation -consumption Co-emergence Leads a Resilience Business.', Innovation and Supply Chain Management, 7:3, pp. 92-104.

Watanabe, C., Kondo, R., Ouchi, N., Wei, H., and Griffy-Brown, C. (2004) 'Institutional Elasticity as a Significant Driver of IT Functionality Development", Technological Forecasting and Social Change, 71:7, pp. 723-750.

Watanabe, C., Naveed, K. and Zhao, W. (2014). 'Institutional Sources of Resilience in Global ICT Leaders - Harness the Vigor of Emerging Power', Journal of Technology Management in Growing Economies, 5:1, pp.7-34.

Watanabe, C., and Zhao, W.(2006) 'Co-evolutionary Dynamism of Innovation and Institution' in Yoda, N., Pariser, R., and Chon, M.C. (Eds.) Chemical Business and Economics. Tokyo. The Chemical Society of Japan , pp. 106-121.

World Bank(2000) A Vision and Strategy of Economic Development of Burma. Washington. World Bank.

World Economic Forum (WEF) (2012) The Global Information Technology Report 2012, 
WEF, Geneva.

World Economic Forum (WEF) (2013a) The Global Competitiveness Report 2013-2014, WEF, Geneva.

World Economic Forum (WEF) (2013b) The Global Information Technology Report 2013, WEF, Geneva.

Zhao, W., Watanabe, C. and Tou, Y. (2013) 'Co-emergence of Institutional Innovation Navigates the New Normal in Growing Economies', Journal of Technology Management in Growing Economies ,4: 1, pp. 69-81.

Khin Sandar, National University of Singapore.

Email: ksandar77@gmail.com.

Chihiro Watanabe, National University of Singapore, University of Jyvaskyla, Finland and International Institute for Applied Systems Analysis (IIASA), Austria. Email: watanabe.c.pqr@gmail.com.
Strategic Option of ICT Driven 